\title{
Studies on neotropical Phasmatodea XVIII: Four new species of Lobolibethra Hennemann \& Conle, 2007 from Peru and Ecuador (Phasmatodea: "Anareolatae": Diapheromeridae)
}

\author{
Frank H. HENNEMANN ${ }^{1, *}$ \& Oskar V. CONLE ${ }^{2}$ \\ ${ }^{1}$ Reiboldstrasse 11, 67251 Freinsheim, Germany. \\ ${ }^{2}$ Am Freischütz 16, 47058 Duisburg, Germany. \\ *Corresponding author: hennemann@phasmatodea.com \\ 22Email: conle@phasmatodea.com \\ ${ }^{1}$ urn:1sid:zoobank.org:author:651FCCFA-271B-48A3-A58E-A30FDC739493 \\ ${ }^{2}$ urn:1sid:zoobank.org:author:D2712C02-7973-4FAA-A186-5F8540A66691
}

\begin{abstract}
Four new species of Lobolibethra Hennemann \& Conle, 2007 (Diapheromerinae: Diapheromerini: "Clonistria-group") are described and illustrated. Lobolibethra carbonelli sp. nov. and L. pozuzoae sp. nov. from eastern Peru are described from both sexes and the eggs, L. tricarinata sp. nov. from southeast Ecuador is described from the female and male, and L. verruculosa sp. nov. from eastern Peru is described from the male. The previously unknown males of the Peruvian L. mainerii (GiglioTos, 1910) and L. mutica Hennemann \& Conle, 2007 are described and illustrated. Dyme iconnicoffi Caudell, 1918 is shown to represent the previously unknown male of L. mainerii (Giglio-Tos, 1910) and is synonymised (syn. nov.). An updated key is presented for the eleven known species of Lobolibethra.
\end{abstract}

Keywords. Phasmatodea, Lobolibethra, new species, descriptions, South America.

Hennemann F.H. \& Conle O.V. 2018. Studies on neotropical Phasmatodea XVIII: Four new species of Lobolibethra Hennemann \& Conle, 2007 from Peru and Ecuador (Phasmatodea: "Anareolatae": Diapheromeridae). European Journal of Taxonomy 449: 1-33. https://doi.org/10.5852/ejt.2018.449

\section{Introduction}

This is the $18^{\text {th }}$ part of an on-going study of the New World Phasmatodea by the authors and presents new information on the genus Lobolibethra Hennemann \& Conle, 2007 including the descriptions of four new species from Peru and Ecuador. The new material at hand broadens our knowledge of this genus and also provides descriptions and illustrations of the previously unknown males of two species. Lobolibethra belongs to a very species-rich complex of the subfamily Diapheromerinae currently regarded as the "Clonistria-group" and the results of the present study show that also Lobolibethra is as yet poorly known and several further new species are awaiting discovery and description. Five of the 11 recognized species are currently only known from single specimens. The wide distributional range appears to include great portions of the Amazon basin and the moist tropical rain forests along the eastern slopes of the Andes up to elevations of almost 2000 metres. Pictures of live specimens 
of various species of Phantasca Redtenbacher, 1906 can be viewed on the authors' website; www.phasmatodea.com.

\title{
Material and methods
}

This study is based on the examination of all type material and has received much support from the curators of all corresponding museums and institutions. The material at hand for this study is exclusively dried and pinned. Insects and eggs were examined using an entomological lens with $4 \times$ magnification and a stereoscope (Zeiss Stemi SV 6). Eggs were examined at 10× magnification. Measurements were taken using a long ruler or a digital caliper and are given to the nearest $0.1 \mathrm{~mm}$. Average measurements are given for eggs. All eggs examined were already laid and hence are fully developed. The terminology used for the descriptions of external and internal egg structures follows that of Clark Sellick (1997 \& 1998). If not explicitly cited and no live material was available, the colouration is described from dried specimens. Collecting data are reproduced exactly as on the labels, and hence are presented in quotation marks.

\section{Abbreviations \\ $\mathrm{FH}=$ Private collection of Frank H. Hennemann, Freinsheim, Germany \\ $\mathrm{OC}=$ Private collection of Oskar V. Conle, Duisburg, Germany}

\section{Institutional abbreviations}

ANSP $=$ Academy of Natural Sciences, Philadelphia, USA
MCSN $=$ Museo Civico di Storia Naturale „Giacomo Doria“, Genova, Italy
MHNG $=$ Muséum d'Histoire naturelle, Geneva, Switzerland
MNCN $=$ Museo Nacional de Ciences Naturales, Madrid, Spain
MNHN $=$ Muséum national d'Histoire naturelle, Paris, France
MNHU $=$ Museum für Naturkunde der Humboldt-Universität, Berlin, Germany
MUSM $=$ Museo de Historia Natural, Universidad Nacional Mayor de San Marcos, Lima, Peru
NHMUK $=$ The Natural History Museum, London, UK
USNM $=$ United States National Museum of Natural History, Washington DC, USA
ZSMC $=$ Zoologische Staatssammlung, Munich, Germany

\section{Results}

\author{
Class Hexapoda Blainville, 1816 \\ Order Phasmatodea Jacobson \& Bianchi, 1902 \\ Infraorder Anareolatae Bradley \& Galil, 1977 \\ Family Diapheromeridae Kirby, 1904 \\ Subfamily Diapheromerinae Kirby, 1904 \\ Tribe Diapheromerini Kirby, 1904
}

Genus Lobolibethra Hennemann \& Conle, 2007

Lobolibethra Hennemann \& Conle, 2007: 90.

Libethra Stål, 1875: 75 (in part).

Ocnophila Brunner v. Wattenwyl, 1907: 309 (in part).

Lobolibethra - Conle, Hennemann \& Gutíerrez 2011: 54.

Ceroys - Westwood 1859: 61, pl. 4, fig. 7.

Libethra-Giglio-Tos 1898: 27. — Kirby 1904: 345 (in part). — Caudell 1918: 6. — Günther 1940: 496, fig. 19. - Otte \& Brock 2005: 175, 176 (in part). 
Dyme - Caudell 1918: 10.

Rugosolibethra - Zompro 2003: 33.

Ceroys (Ceroys) - Zompro 2004: 180.

Ocnophila - Giglio-Tos 1910: 30. — Otte \& Brock 2005: 229 (in part).

\section{Type species}

Lobolibethra panguana Hennemann \& Conle, 2007: 98, by original designation.

\section{Comments}

The original generic description and differentiation presented by Hennemann \& Conle (2007) is very detailed and requires no additions. As previously pointed out, females of Lobolibethra are easily distinguished from those of the closely related Libethra Stål, 1875 by the more convex, strongly keeled and posteriorly entire, rounded or truncate subgenital plate and males are readily distinguished by the small unspecialized cerci. It is, however, noteworthy that the subgenital plate of females has the apex gently concave and excavated in L. mainerii (Caudell, 1918) and L. ramale (Giglio-Tos, 1898), but not as deeply incised as in Libethra. The eggs differ by the less elongate capsule, which is almost circular in lateral aspect, and comparatively longer micropylar plate.

Like numerous species of the related Libethra, females of several species are very polymorphic and show strong intraspecific variability, which concerns the sculpturing of the body and armature of the extremities. Consequently, the presence or absence of strumae and lobes on the abdominal tergites, degree of thoracic nodes or tubercles, as well as the size and shape of teeth or lobes on the legs of females are only of limited value for species distinction. This is very well shown by the large type series of L. panguana Hennemann \& Conle, 2007, which includes 82 females and allows a fairly good overview of the range of intraspecific variability in the genus. Genital characters, like the shape of the anal segment (= abdominal tergum X), subgenital plate and the praeopercular organ on abdominal sternum VII, as well as length relations of body segments, have proven by far more reliable for distinguishing and characterizing species. Characters such as the sculpturing of the body and armature of the legs are here only used as key features if they represent extreme states, e.g., are strongly developed or almost to completely lacking.

\section{Distribution}

Moist tropical rain forests below $2000 \mathrm{~m}$ in southeast Ecuador, southeast Colombia, eastern and central Peru, central Brazil and central Bolivia. According to Morrone (2006: 472-473) the known distribution refers to the Amazonian subregion of the Neotropical region (biogeographical Provinces Yungas, Napo, Varzea, Ucayali and Madeira) and to the eastern sections of the South American Transition Zone (biogeographical Province Puna).

The currently known records of Lobolibethra clearly show that the genus is still poorly known and the distribution is believed to cover most of the northern tropical lowlands and Amazon basin of South America.

\section{Species included}

1. Lobolibethra acheloa (Günther, 1940: 496) [Libethra] (Southeast Colombia, Dept. Amazonas, Río Tacana)

2. Lobolibethra boliviana Hennemann \& Conle, 2007: 93, figs 1, 3-6 (Central Bolivia, Chapare Prov., Río Chapare, Villa Tunari, $320 \mathrm{~m}$ a.s.1.)

3. Lobolibethra carbonelli sp. nov. (East Peru, Dept. Huánuco, Tingo Maria, 660 m a.s.1.) 
4. Lobolibethra ignava (Westwood, 1859: 61, pl. 4, fig 7) [Ceroys] (Northeast Brazil, Pará State, Río Tapajós)

5. Lobolibethra mainerii (Giglio-Tos, 1910: 30) [Ocnophila]

= Libethra peruana Caudell, 1918: 6

= Dyme iconnicoffi Caudell, 1918: 10. syn. nov. (Southeast Peru: Dept. Junín, San Ramón, 770 m a.s.l. and Dept. Junín, Río Carhuamayo)

6. Lobolibethra mutica Hennemann \& Conle, 2007: 96, figs 2, 7-10 (North Peru)

7. Lobolibethra panguana Hennemann \& Conle, 2007: 98, figs 11-23, 32-33, 38-40 (East Peru, Dept. Huánuco, Rio Yuyapichis, Panguana, 260 m a.s.l.; Dept. Tambopata, Tambopata Nature Reserve, Río Madre de Dios; Dept. Madre de Dios, Manú National Park)

8. Lobolibethra pozuzoae sp. nov. (East Peru, Dept. Pasco, Pozuzo, $800 \mathrm{~m}$ a.s.1.)

9. Lobolibethra ramale (Giglio-Tos, 1898: 27) [Libethra] (Southeast Ecuador, Zamora Chinchipe Prov., San Jose, 1430 m a.s.1.)

10. Lobolibethra tricarinata sp. nov. (South Ecuador, El Oro Prov., 5-9 km E of Piñas, 900-950 m a.s.1. and Zamora Chinchipe Prov., El Salado, 1310 m a.s.1.)

11. Lobolibethra verruculosa sp. nov. (East Peru, Dept. Huánuco, San Luis de León Pampa)

\section{Keys to species of Lobolibethra}

\section{Females*}

1. Hind legs unarmed (at most with a single small sub-basal dorsal lobe on metatibiae) ...........2

- All three pairs of legs with various lobes of variable sizes .................................

2. Mesofemora at least with small lobules ventrally; subgenital plate obtusely rounded apically ...3

- Mesofemora entirely smooth; subgenital plate acutely pointed apically (S Ecuador)

L. tricarinata sp. nov.

3. Ventral lobes of mesofemora prominent and much wider than diameter of femur ................4

- Ventral lobes of mesofemora small and no larger than diameter of femur .......................5

4. Epiproct small and not considerably projecting over posterior margin of anal segment

L. acheloa (Günther, 1940)

- Epiproct enlarged, triangular and projecting distinctly beyond apex of anal segment (NE Brazil) ......

L. ignava (Westwood, 1859)

5. Lateral margins of anal segment deflexed; subgenital plate convex, tub-shaped

- Lateral margins of anal segment not deflexed and converging towards posterior; subgenital plate fairly flat, scoop-shaped L mutica (Hennemann \& Conle, 2007)

6. Stocky insects; mesothorax $3.6 \times$ as long as prothorax; anal segment with a distinct triangular median indention L. carbonelli sp. nov.

- More slender insects; mesothorax $>4 \times$ as long as prothorax; anal segment with posterior margin quadri-dentate

L. pozuzoae sp. nov.

7. Anteroventral carina of metafemora at most with minute, rounded lobes; metatibiae without a subbasal ventral lobe; subgenital plate gently excavated apically $\ldots \ldots \ldots \ldots \ldots \ldots \ldots \ldots \ldots \ldots \ldots . \ldots \ldots$

- Metafemora with large foliaceous lobes on anteroventral carina; metatibiae with a distinct subbasal ventral lobe; subgenital plate with apex rounded

8. Body length $>50 \mathrm{~mm}$; slender insects; mesothorax $4.3 \times$ as long as prothorax; abdominal segments III-V longer than wide; mesofemora with three small, rounded lobes on anteroventral carina (S Ecuador). L. ramale (Giglio-Tos, 1898) 
- Body length $<50 \mathrm{~mm}$; more stocky insects; mesothorax at most $3.4 \times$ as long as prothorax; abdominal segments III-IV wider than long; mesofemora with two prominent lobes on anteroventral carina (E Peru) L. mainerii (Giglio-Tos, 1910)

9. Stocky insects; mesothorax about $4.4 \times$ as long as prothorax; median segment about $1 / 3$ the length of metanotum; profemora longer than mesothorax (Bolivia)

L. boliviana (Hennemann \& Conle, 2007)

- More slender insects; mesothorax almost $5 \times$ as long as prothorax; median segment less than $1 / 4$ the length of metanotum; profemora about as long as mesothorax (E Peru)

L. panguana (Hennemann \& Conle, 2007)

\section{Males**}

1. Meso- and metathorax granulose, nodulose or verruculose 2

- Meso- and metathorax smooth (Peru) L. pozuzoae sp. nov.

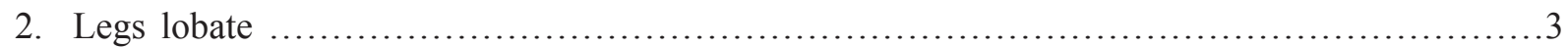

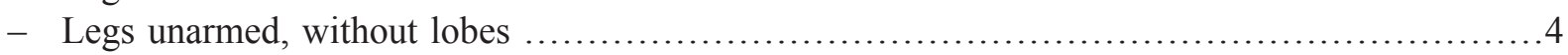

3. Very slender insects; mesothorax almost $7 \times$ as long as prothorax; mesonotum with irregularly dispersed small granules and nodules; mesofemora unarmed dorsally

L. panguana (Hennemann \& Conle, 2007)

- More stocky insects; mesothorax $<6 \times$ as long as prothorax; mesonotum with single enlarged yellow tubercles; mesofemora with 3-4 small lobules dorsally ...L. mainerii (Giglio-Tos, 1910)

4. Slender insects, abdominal segments III-V $>2 \times$ as long as wide; meso- and metathorax granulose

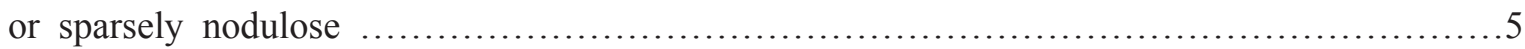

- Stocky insects, abdominal segments III-V $<2 \times$ as long as wide: meso- and metathorax densely

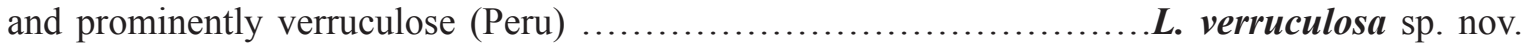

5. Anal segment not longer than wide and distinctly deflexed medially; abdominal tergites II-V without carinae (Peru) .................................................................

- Anal segment longer than wide and very weakly deflexed post-medially; abdominal tergites II-V carinate ( $\mathrm{S}$ Ecuador)

L. tricarinata sp. nov.

6. Very slender insects; mesothorax $6.5 \times$ as long as prothorax; mesonotum only supplied with single nodes; poculum small and reaching only about half way along tergum IX

L. mutica (Hennemann \& Conle, 2007)

- More stocky insects; mesothorax only $5.5 \times$ as long as prothorax; mesonotum densely granulose; poculum large and reaching to posterior margin of tergum IX L. carbonelli sp. nov.

* Females of L. verruculosa sp. nov. are not known.

** Males of L. acheloa (Günther, 1940), L. boliviana Hennemann \& Conle, 2007, L. ignava (Westwood, 1859) and L. ramale (Giglio-Tos, 1898) are not known.

Lobolibethra carbonelli sp. nov. urn:1sid:zoobank.org:act:881B5F7B-A260-4F08-9E84-17C6B3BD178A

Figs $1-13,56-58$

\section{Diagnosis}

Closely related and similar to L. pozuzoae sp. nov. but differing by the on average smaller size, somewhat more stocky body and relatively shorter body segments of both sexes. Females may also be distinguished by the presence of two small cephalid spines, the more convex and bulgy subgenital plate (Fig. 7), which 
has the lateral margins less excavated and the lateral surfaces each supplied with about three blunt projections (Fig. 8), medially indented posterior margin (Fig. 6) and less deflexed lateral margins of the anal segment and more prominent ventral lobes of the mesofemora. Males are readily distinguished by the granulose to nodulose meso- and mesonotum (Fig. 5, smooth in L. pozuzoae sp. nov.), lack of a concave posterior excavation of the lateral margins of the anal segment (Fig. 10) and more rugulose poculum, which has the posterior margin indented medially (Fig. 11). The eggs differ by the slightly more elongate capsule and longer micropylar plate, which covers almost $3 / 4$ of the dorsal egg-surface (Figs $12-13$, only $2 / 3$ in L. pozuzoae sp. nov.).

\section{Etymology}

Named after C. S. Carbonell, who collected the holotype and paratypes in the collection of MNHU.

\section{Material examined}

\section{Holotype}

PERU: + , "Peru, Tingo Maria - 16.07.1948 (Nachtfang im Wald), leg. C.S. Carbonell; Uruguay Expedition, Dr. K.K. Günther April - Juni 1948; Dept. Ent. Montevideo Uruguay” (MNHU).

Paratypes (130 $\hat{\jmath}, 126$ 우, eggs)

PERU: 2 ठึ, 1 ค, "Peru, Tingo Maria - 16.07.1948 (Nachtfang im Wald), leg. C.S. Carbonell; Uruguay - Expedition, Dr. K.K. Günther April - Juni 1968; Dept. Ent. Montevideo Uruguay” (MNHU); 1 กิ, 1 ㅇ, "Peru, Tingo Maria - 16.07.1948 (in Copula), leg. C.S. Carbonell; Uruguay - Expedition,

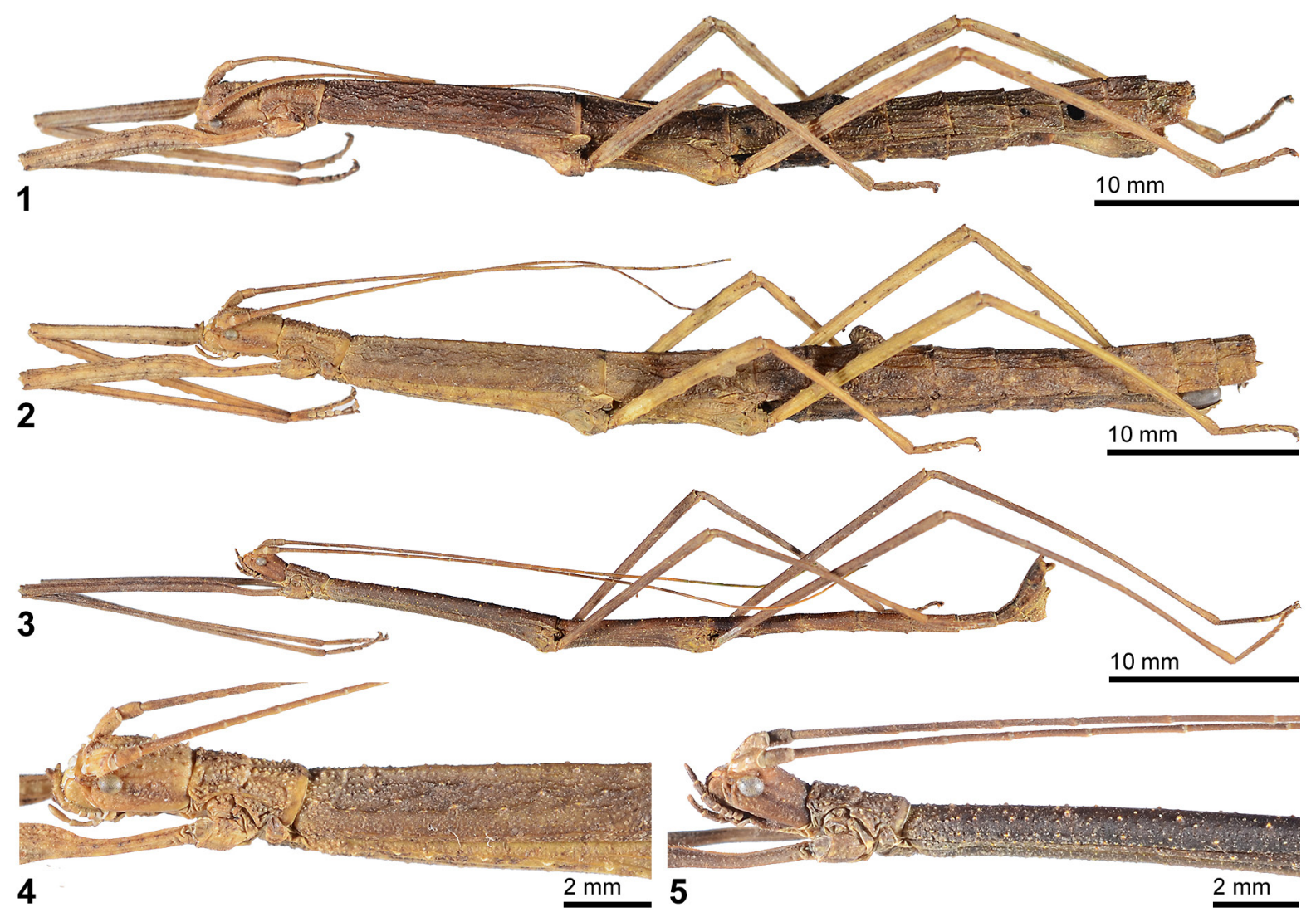

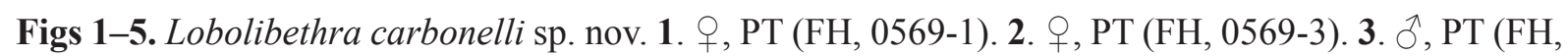
0569-15). 4. + , PT: detail of head and thorax in lateral view (FH, 0569-3). 5. $0^{\top}$, PT: detail of head and thorax in lateral view (FH, 0569-15). 
Dr. K.K. Günther April - Juni 1968; Dept. Ent. Montevideo Uruguay" (MNHU); 1 dૈ, "Peru, Tingo Maria, IV, V-1952, P. Araoz" (USNM); 1 ㅇ, "Peru: Tingo Maria, IV \& V.52 night, Pedro Araoz" (USNM);

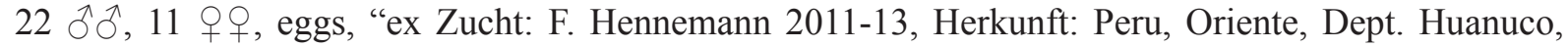
Tingo Maria, 2010" (FH, 0569-1-33 and E1); 4 eggs, "Libethra PSG 51, Peru, Tingo Maria; ex coll. J.T. Clark Sellick” (FH, 0569-E2); 62 §ิô, 64 우, eggs, "Ex Zucht: O. Conle 2011-12, Peru: Oriente,

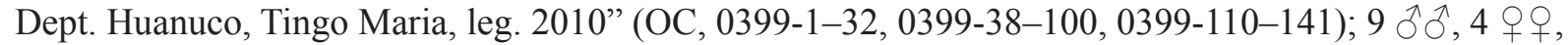
"Ex Zucht: B. Kneubühler 2010, Peru: Oriente, Dept. Huanuco, Tingo Maria, Gen F1, leg. 2010" (OC, 0399-33-36, 0399-101-109); +, "Ex Zucht: B. Kneubühler 2011, Peru: Oriente, Dept. Huanuco, Tingo Maria, Gen F2, leg. 2010" (OC, 0399-37); 33 đ̄ô, 43 우우, eggs, "Ex Zucht: O. Conle 2011-12, Peru: Oriente, Dept. Huanuco, Tingo Maria, leg. 2010; Ex Coll. Conle" (ZSMC).

\section{Description}

Female (Figs 1-2, 57-58)

Body. Size fairly small (body length 48.5-53.2 mm, Table 1), form stocky, body surface tuberculose, rugulose and carinate (abdomen in particular) and mid and hind legs moderately lobed. Abdominal tergites III and IV mostly with a transverse scale-like posteromedian lobe, which is very variable in shape and size (small on IV although).
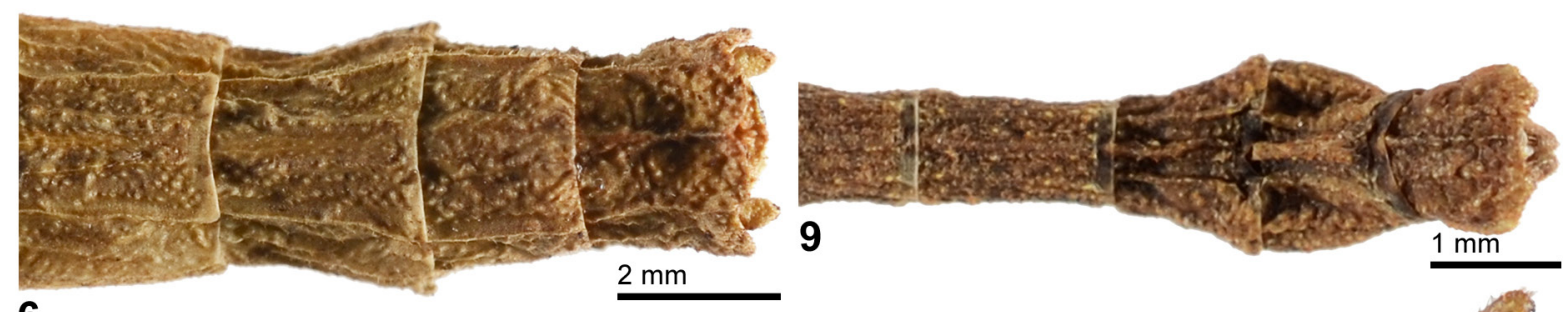

6
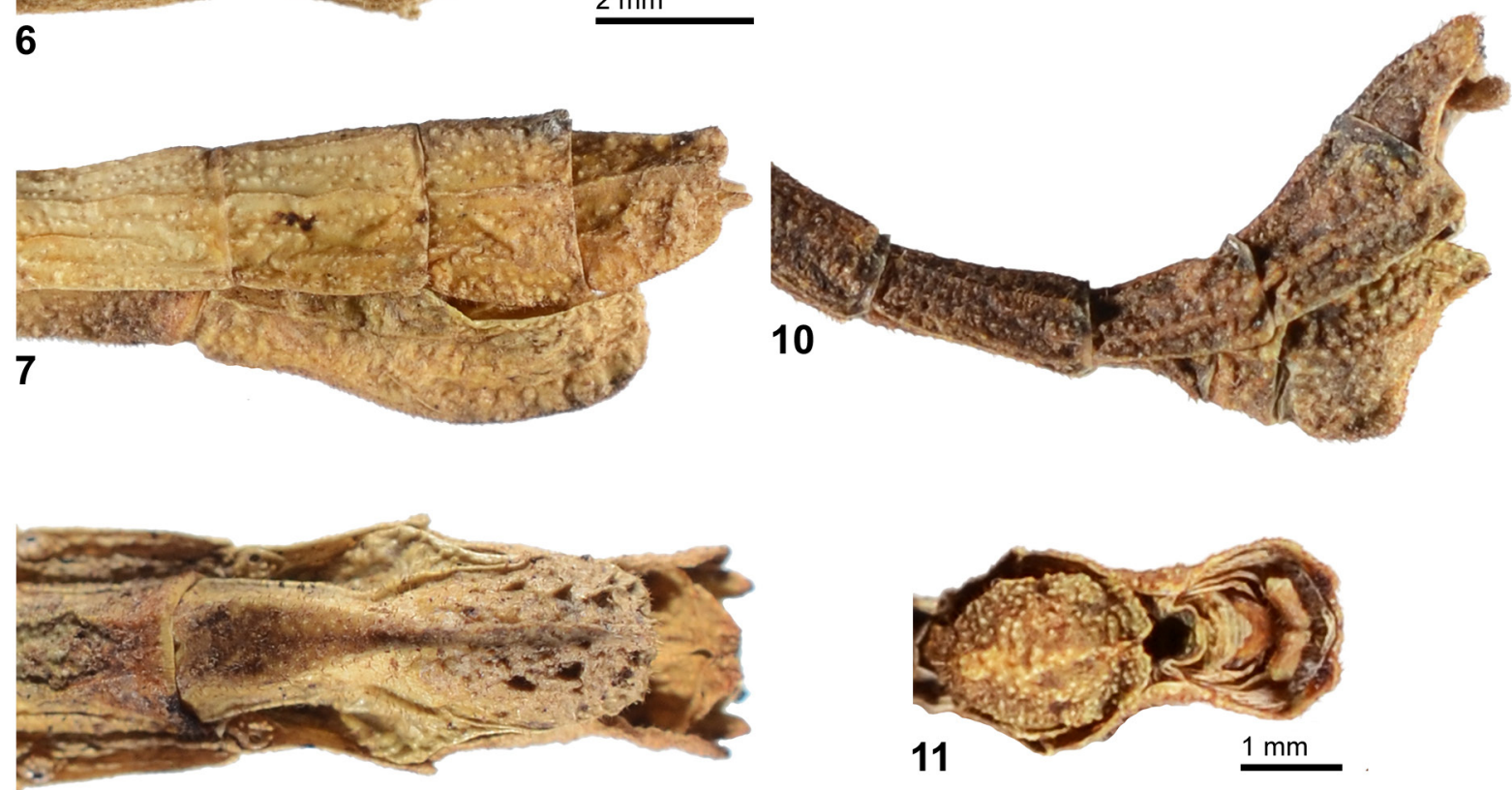

8

Figs 6-11. Lobolibethra carbonelli sp. nov. 6. ㅇ, PT: apex of abdomen in dorsal view (FH, 0569-10). 7. $ᄋ$, PT: apex of abdomen in lateral view (FH, 0569-11). 8. ㅇ, PT: apex of abdomen in ventral view

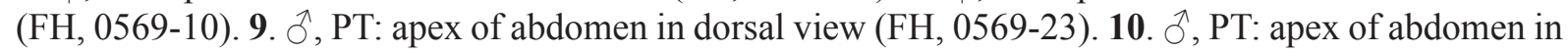
lateral view (FH, 0569-20). 11. Oे, PT: apex of apex of abdomen in ventral view (FH, 0569-23). 
Table 1. Measurements of $L$. carbonelli sp. nov. (in $\mathrm{mm}$ ). HT = holotype; $\mathrm{PT}=$ paratype.

\begin{tabular}{|c|c|c|c|c|c|}
\hline & $\begin{array}{c}\text { O, HT } \\
\text { (MNHU) }\end{array}$ & $\begin{array}{c}\hat{\partial} \hat{O}, \mathbf{P T} \\
\text { (MNHU) }\end{array}$ & $\begin{array}{c}\text { oq, PT } \\
\text { (MNHU) }\end{array}$ & $\begin{array}{c}\hat{\partial} \hat{O}, \mathbf{P T} \\
\text { (FH) }\end{array}$ & $\begin{array}{c}+ \text { q, PT } \\
\text { (FH) }\end{array}$ \\
\hline Body & 49.2 & $42.0-43.5$ & $49.0-49.8$ & $36.0-45.0$ & $48.5-53.2$ \\
\hline Pronotom & 2.6 & $1.7-1.8$ & $2.7-2.8$ & $1.6-1.8$ & $2.7-3.0$ \\
\hline Mesonotum & 12.4 & $12.0-12.1$ & $12.1-12.6$ & $9.5-13.0$ & $12.2-13.0$ \\
\hline Metanotum & 5.6 & $6.7-6.8$ & $5.2-5.4$ & $5.7-6.9$ & $5.3-5.6$ \\
\hline Median segment & 1.7 & 1.8 & $1.7-1.8$ & $1.7-1.8$ & $1.7-1.9$ \\
\hline Profemora & 13.2 & $13.8-14.2$ & $11.9-12.6$ & $12.0-13.9$ & $11.8-12.5$ \\
\hline Mesofemora & 9.2 & $9.8-10.1$ & $8.4-8.6$ & $9.3-10.4$ & $8.5-9.5$ \\
\hline Metafemora & 12.3 & $13.6-14.8$ & $11.2-11.5$ & $11.3-14.3$ & $11.6-12.9$ \\
\hline Protibiae & 13.3 & $15.3-16.0$ & $12.7-13.4$ & $13.4-16.2$ & $11.8-13.3$ \\
\hline Mesotibiae & 9.8 & $11.9-12.0$ & $9.0-9.3$ & $10.0-12.0$ & $9.3-10.0$ \\
\hline Metatibiae & 14.8 & $16.2-17.3$ & $13.1-14.1$ & $13.4-17.6$ & $12.6-13.5$ \\
\hline Antennae & 27.0 & $29.0-34.0$ & 22.7 & $28.0-35.0$ & $24.0-29.0$ \\
\hline
\end{tabular}

CoLour. Colour variable, ranging from dull ochre to dark greyish brown, sometimes with indicated longitudinal stripes or slightly greenish portions. Meso- and metapleurae usually with a marginal row of dark markings in pale specimens. Antennae pale to dark brown.

HEAD. Elongate-oval with cheeks very gently narrowing towards posterior and vertex flattened; about $1.2 \times$ as long as wide. Posterior portion of vertex distinctly tuberculose and a few dispersed tubercles also on cheeks; two tubercles at posterior margin somewhat enlarged and spiniform and a pair of short, conical spines roughly in centre of vertex. Eyes small, sub-circular and their length contained about 2.6× in that of cheeks. Antennae reaching to posterior margin of abdominal segment III. Scapus compressed dorsoventrally, rounded rectangular, with lateral margins very gently deflexed and rounded; about $1.2 \times$ as long as wide. Pedicellus cylindrical and somewhat tapered towards apex. Antennomere III very elongate and almost as long as scapus and pedicellus combined; IV less than $1 / 4$ length of III.

Thorax. Pronotum about as wide as but a little shorter than head, rectangular in shape, about $1.2 \times$ as wide as long and somewhat narrowed medially. Transverse median sulcus midways on prothoracic disc, moderately impressed, gently curved and expanding over entire width of segment. Surface densely granulose and tuberculose, with two tubercles just in front of median sulcus slightly more pronounced. Mesothorax about $3.8 \times$ as long as prothorax, parallel-sided, with only posterior portion gently widened. Mesonotum bluntly tectiform, irregularly granulose, tuberculose and rugulose; rugulae longitudinally directed and several of these raised to form a blunt tubercular swelling (Fig. 4). An irregularly interrupted carina along lateral margins. Metanotum sculptured like mesonotum but lacking noticeably enlarged tubercles. Meso- and metanotum both with a more or less decidedly enlarged pair of blunt tubercles posteromedially. Meso- and metapleurae with a fine longitudinal carina roughly midways and a marginal 
row of about 7-8 (mesopleurae) or 3-4 (metapleurae) blunt tubercles. Meso- and metasternum granulose and supplied with some irregularly dispersed small tubercles.

ABDomen. Median segment a little more than $1 / 3$ length of metanotum and almost $2 \times$ as wide as long; surface like metanotum and usually with a somewhat enlarged pair of blunt tubercles posteromedially. Segments II-III slightly widening and increasing in length, IV parallel-sided and V-VII slightly narrowing and decreasing in length; IV widest and longest segment, roughly quadrate. II transverse and shorter than VII. Tergites II-IX with four longitudinal, sub-parallel carinae (most decided on II and VII-IX) and II-VII with three small, blunt nodes at lateral margins; otherwise minutely granulose and occasionally with a further very faint carina laterally. Two inner carinae supplied with some blunt tubercles on VII-IX and on latter two tergites often terminating in a rounded lobe or obtuse swelling. Tergum III mostly with a fairly large, transverse, scale-like lobe, which spans between the two outer carinae and is very variable in size and shape (rarely obsolete). Often also a much smaller, somewhat bowl-shaped posteromedian lobe on tergum IV. Sternites II-VII granulose, with a fine and irregularly interrupted longitudinal carina laterally and two blunt, irregular, sub-parallel carinae medially, each of which terminates in a small, blunt swelling at posterior margin; otherwise granulose and minutely tuberculose. Praeopercular organ indistinct. Tergum VIII somewhat widening towards posterior, IX shorter than VIII and roughly quadrate, both with a fairly acute longitudinal median carina; two inner lateral carinae occasionally protruded into a bluntly rounded lobe posteriorly. Anal segment equal in length to IX, with lateral margins roughly parallel-sided in dorsal aspect, moderately deflexed and bluntly rounded; dorsal surface with a very acute longitudinal median keel and posterior margin almost straight, with a shallow median indention (Fig. 6). Epiproct fairly large, broadly rounded, transverse and very slightly projecting over posterior margin of anal segment (Fig. 6). Cerci small, conical, compressed dorsoventrally and slightly projecting beyond anal segment. Subgenital plate reaching about half way along anal segment, tub-shaped, with apical half strongly convex and keeled longitudinally (Fig. 7); basal portion compressed laterally, dorsal margins weakly excavated and concave in apical half and apex obtusely rounded. Surface irregularly rugulose and tuberculose and each lateral surface in apical half with three conspicuous spiniform projections (Fig. 8).

Legs. All fairly short and stocky, profemora about equal in length to mesothorax and metafemora roughly reaching to posterior margin of abdominal segment VI. Anterodorsal carina of profemora weakly undulate and anterodorsal carina of protibiae with several weakly developed, blunt lobules. Dorsal carinae of mesofemora weakly undulate and anteroventral carina with three rounded lobes that increase in size towards apex; terminal sub-apical lobe variable in size. Two dorsal carinae of meso- and metatibiae with a small, blunt tooth-like lobe sub-basally. All tarsi short, with basitarsus about as long as following two tarsomeres combined.

Male (Figs 3, 56)

Body. Size fairly small (body length 42.0-45.0 mm, Table 1), form moderately slender for the genus; thorax granulose and nodulose.

CoLour. Plain, mid to dark greyish brown, head and extremities usually with a slight reddish hue. Lateral surfaces of meso- and metathorax as well as meso- and metapleurae dull greenish in live specimens. All tubercles and nodes of thorax and abdomen ochre to dull yellow (Fig. 5). Antennae reddish mid brown.

HEAD. Sub-oval, broadest at eyes, with cheeks slightly sub-parallel and narrowing towards posterior; vertex flattened, minutely granulose and with a small pair of tubercles roughly in centre, a similarly sized pair at posterior margin and 2-3 small tubercles on cheeks. Eyes sub-circular strongly projecting and their length contained about $1.9 \times$ in that of cheeks. Antennae reaching to abdominal segment VI; otherwise as in females. 
THORAX. Pronotum somewhat shorter and narrower than head as in females but with sculpturing less decided. Mesothorax a little more than $5 \times$ as long as prothorax. Surface of meso- and metanotum minutely granulose, mesonotum with about six somewhat enlarged nodes in median portion (Fig. 5); both with a longitudinal row of small tubercles along lateral margins. Meso- and metapleurae with a longitudinal median row of minute tubercles and about 3-4 slightly enlarged tubercles. Meso- and metasternum granulose.

AbDomen. Median segment less than 1/5 length of metanotum, roughly quadrate in outline. Segments II-VII uniform in width, II-V slightly increasing and VI-VII decreasing in length; VII shorter than II. $\mathrm{V}$ longest segment and about $2 \times$ as long as wide. Tergites II-V very minutely granulose, VI and VII increasingly rugulose and VII with a blunt longitudinal median carina. Sternites very minutely and sparsely granulose. Tergum VIII trapezoidal and distinctly widened towards posterior, with posterior margin about $1.3 \times$ as wide as anterior margin; surface irregularly granulose and with five blunt longitudinal carinae, of which median carina is most decided. IX about equal in length to VIII, narrowed towards posterior, slightly tectiform and with carinae noticeably more decided than on VIII; outer lateral carina in particular very blunt and irregularly scabrous. Anal segment shorter than preceding, constricted basally, with lateral margins strongly deflexed in median portion (Fig. 9); dorsal surface with a fine longitudinal median carina; posterior margin with a shallow median excavation and outer angles bluntly triangular (Fig. 9), somewhat swollen and supplied with several minute black denticles ventrally (Fig. 11). Cerci short, gently curved and slightly club-shaped, with an obtuse apex. Vomer well developed triangular and with a fairly short but acute, straight terminal hook; dull reddish brown. Poculum moderately convex, bowl-shaped, with complete surface strongly rugulose and scabrous; posterior margin weakly labiate and with a distinct, rounded median indention (Fig. 11).

Legs. All long, slender and completely unarmed. Profemora almost as long as pro- and mesothorax combined, metafemora reaching to abdominal segment VIII and metatibiae projecing considerably beyond apex of abdomen. Tarsi moderately elongate, with basitarsus a little longer than following three tarsomeres combined.

Egg (Figs 12-13)

Small, globose, $1.25 \times$ as long as high and about $1.8 \times$ as long as wide, compressed laterally and oval in cross-section, with dorsal portion strongly convex. Capsule surface strongly shiny and very minutely granulose if seen in strong magnification. Micropylar plate elongate, slender, almost parallel-sided with
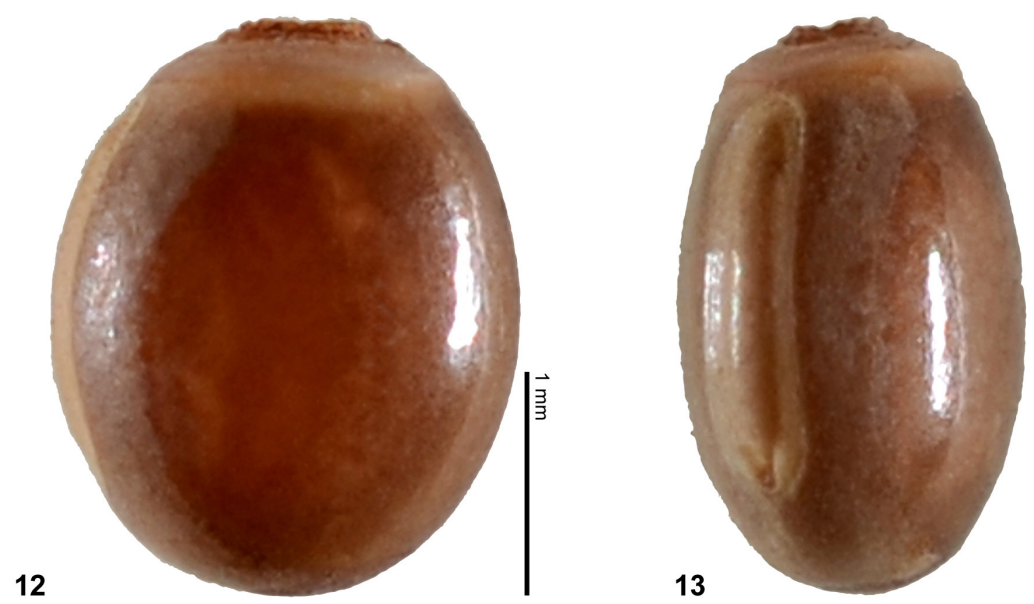

Figs 12-13. Lobolibethra carbonelli sp. nov. 12. Egg, PT: lateral view (FH, 0569-E1); 13. Egg, PT: dorsal view (FH, 0569-E1). 
only posterior portion very gently widened and about $3 / 5$ length of capsule. Central portion raised and gently convex. Micropylar cup small and near posterior end of plate, median line very indistinct and reaching about $2 / 3$ to polar area. Operculum elliptical, gently downcurving dorsally and flat. In centre with a rim of irregularly shaped tubercles and short projections. When newly laid, the eggs are black with dorsal surface creamish mid grey. Older or incubated eggs that have already come in contact with humidity tend to become increasingly pale, being reddish mid brown. Micropylar plate dull cream, with outer marginal portion pale cream. Outer margin of operculum grey and opercular structures dull yellow or straw (reddish brown in older eggs). Measurements (in mm): length 2.6, capsule length 2.5, width 1.4, height 1.9 , length of micropylar plate 1.9 .

\section{Remarks}

As usual for the more cryptic species in the genus, considerable variability is seen in the sculpturing of the abdominal tergites of females. The scale-like posterior lobe of abdominal tergum III is variable in size and shape, and occasionally there is a further much smaller lobe on tergum IV. More rarely both lobes are obsolete. Some specimens may also have a pair of small posterior lobes on abdominal tergum IX. The size of the ventral lobes of the mesofemora shows quite some variability as well, and while the metatibiae are unarmed in most specimens at hand, there may occasionally be a small sub-basal lobe on the posterodorsal carina. Considerable variation is also seen in colouration.

The type locality Tingo Maria is situated at the junction of Río Monzón and Río Huallaga at an elevation of about $660 \mathrm{~m}$ in the Huánuco region of Leoncio Prado Province in eastern Peru. The coordinates are $9^{\circ} 18^{\prime} \mathrm{S}, 76^{\circ} 0^{\prime} \mathrm{W}$.

Culture stock from the type-locality was first imported to Europe in 1992 by Allan J.E. Harman (Essex, UK), but the culture was lost after a few generations. This culture was included on the Phasmid Study Group culture-list as PSG No. 51. A second stock from the type locality was imported in 2010 and first reared by Bruno Kneubühler (Luzern, Switzerland). Bramble (Rubus fruticosus, Rosaceae), raspberry (Rubus idaeus, Rosaceae), roses (Rosa spp., Rosaceae) and oak (Quercus robur, Fagaceae) were accepted as alternative food plants. In captivity males reached maturity after about three months, while females took about four months to reach maturity at average temperatures of $20-24{ }^{\circ} \mathrm{C}$. Females produced an average of 10-12 eggs per week, which were simply dropped to the ground.

Lobolibethra mainerii (Giglio-Tos, 1910)

Figs 14-19

Ocnophila mainerii Giglio-Tos, 1910: 30.

Libethra peruana Caudell, 1918: 6 (synonymised by Hennemann \& Conle 2007: 95).

Dyme iconnicoffi Caudell, 1918: 10. Syn. nov.

Ocnophila mainerii - Otte \& Brock 2005: 229.

Libethra peruana - Otte \& Brock 2005: 176. — Hennemann \& Conle 2007: 95.

Bacteria iconnicoffi - Otte \& Brock 2005: 64.

Lobolibethra mainerii - Hennemann \& Conle 2007: 95.

\section{Material examined}

\section{Holotype}

PERU: Holotype (of Ocnophila mainerii Giglio-Tos, 1910), $q$, "Rio Chanchamayo, Peru, 1896-1898, Pesce Mainer; Holotype + Ocnophila mainerii Giglio-Tos, 1910; Ocnophila mainerii Giglio-Tos $q$

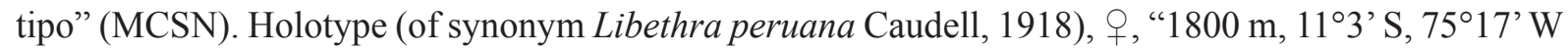
Greenw., N. Iconnicoff 4.12.06; Libethra peruana Caud. + Type” (USNM). 


\section{Paratype}

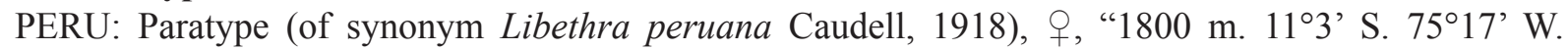
Greenw., N. Iconnicoff 4.12.06; Libethra peruana Caud. क Paratype "a"; Type No. 21321 U.S.N.M." (USNM); Paratype (of synonym Libethra peruana Caudell, 1918), +, " $11^{\circ} 3^{\prime}$ ' S. 75¹7' W. Greenw., VIII.08, C. Schunke; Libethra peruana Caud. ㅇ Para-type "b"' (USNM); Holotype (of synonym Dyme

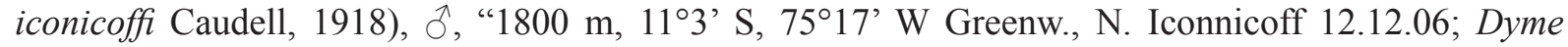
iconnicoffi Caud. ¿̊ Type" (USNM).

\section{Other material}

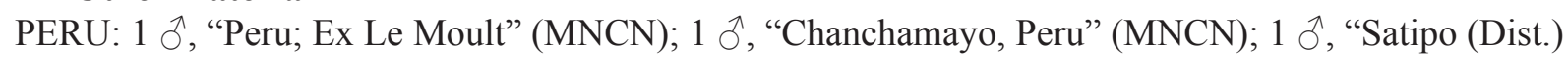
Peru" (ANSP).

\section{Remarks}

The availability of very detailed pictures of the male holotype of Dyme iconnicoffi Caudell, 1918 in the collection of the USNM shows the specimen to bear exactly the same characteristics as the three female

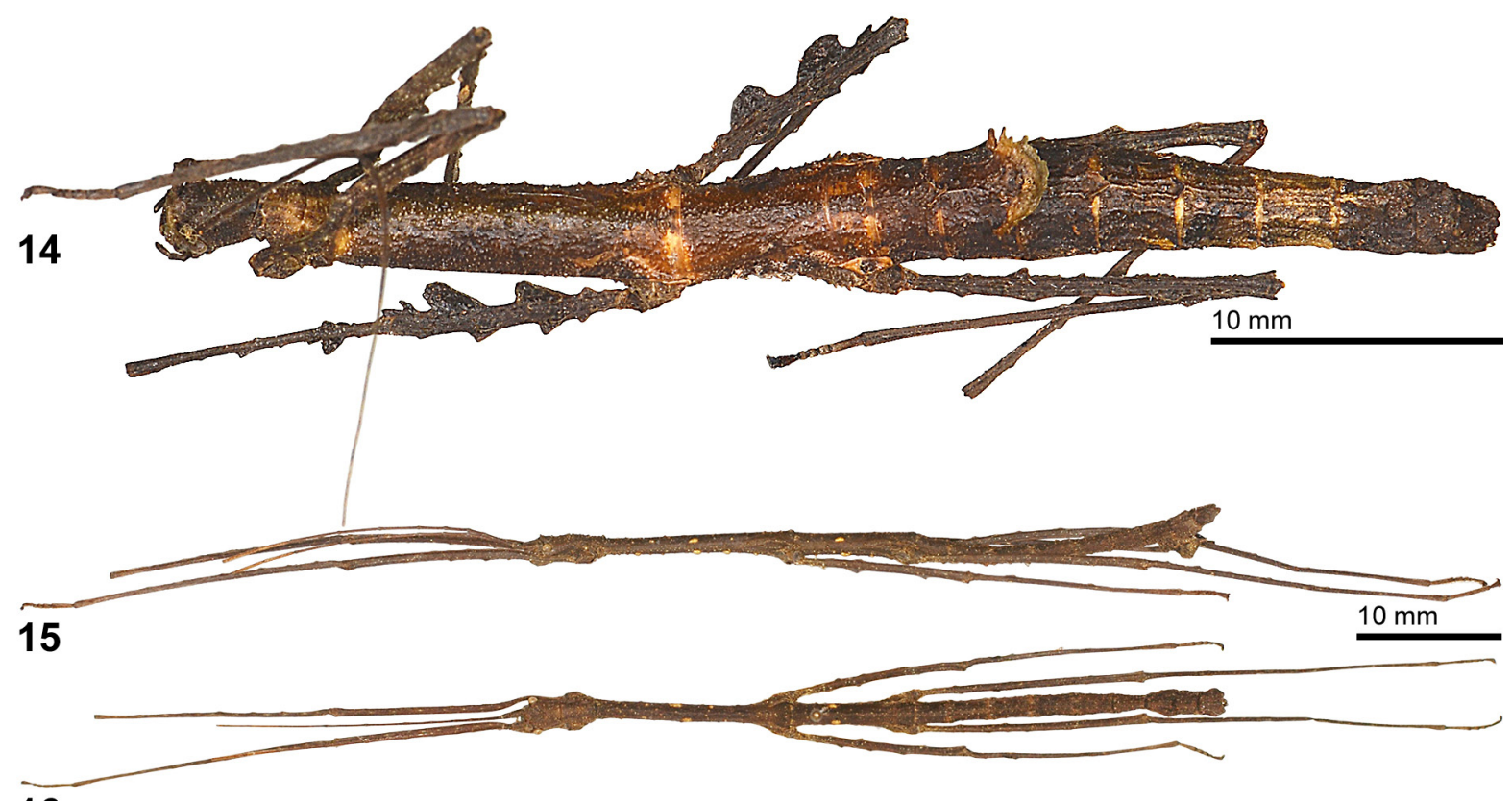

16

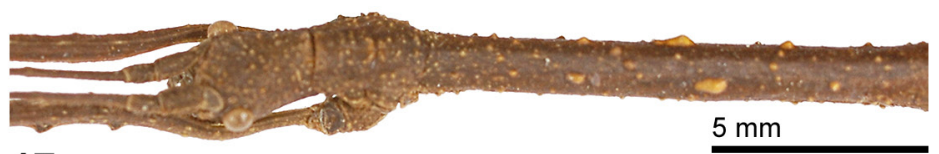

17
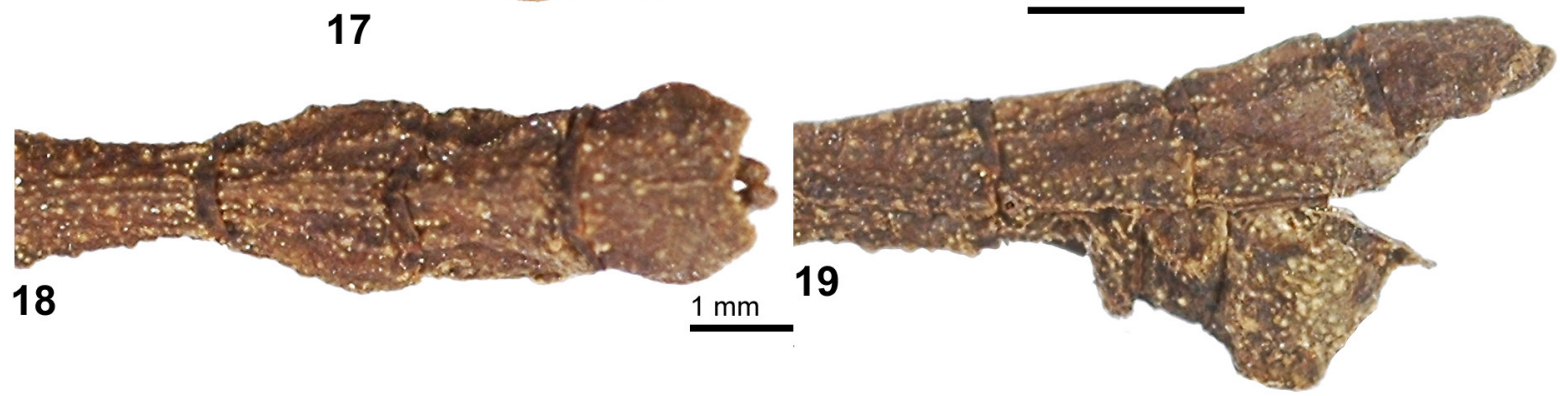

Figs 14-19. Lobolibethra mainerii (Giglio-Tos, 1910), 14. ㅇ, HT of synonym L. peruana Caudell, 1918 (USNM). 15. $\sigma^{\lambda}$, lateral view (MNCN). 16. $\partial^{\lambda}$, dorsal view (MNCN). 17. $\partial^{\lambda}$, detail of head and thorax in dorsolateral view (MNCN). 18. $\sigma^{\lambda}$, apex of abdomen in dorsal view (MNCN). 19. $\delta$, apex of abdomen in lateral view (MNCN). 
type specimens of Lobolibethra peruana (Caudell, 1918; Fig. 14) and comparison leaves no doubt that these specimens are the opposite sexes of the same species. Consequently, D. iconnicoffi represents the previously unknown male of L. mainerii (Giglio-Tos, 1910) and is a junior synonym (syn. nov.). Two males were traced to the collection of MNCN, one of which is from Río Carhuamayo, the type locality of $L$. mainerii. These two specimens have body lengths of $47.6 \mathrm{~mm}$ and $49.0 \mathrm{~mm}$ (Figs 15-16). A male from Satipo in ANSP is remarkable for being more slender and remarkably larger, with a body length of $58.0 \mathrm{~mm}$.

Males of L. mainerii resemble those of L. panguana Hennemann \& Conle, 1907 in aspect of the body sculpturing and leg armature, but readily differ by the much smaller size as well as the considerably more stocky body and relatively shorter body segments. They are well characterized by the presence of several variably sized and irregularly dispersed yellow tubercles and nodes on the head and thorax, including the meso- and metasternum (Fig. 17).

As already mentioned by Hennemann \& Conle (2007: 96), the type locality "Rio Chanchamayo" presumably refers to the present Río Carhuamayo, an affluent of Río Perené which joins it near San Ramón (Dept. Junín), and the coordinates given for Caudell's type specimens (113' S, $\left.75^{\circ} 17^{\prime} \mathrm{W}\right)$ refer to a place some 20 kilometres northwest of Satipo (Dept. Junín).

The eggs still remain unknown.

Lobolibethra mutica Hennemann \& Conle, 2007

Figs 20-23

Lobolibethra mutica Hennemann \& Conle, 2007: 96, figs 2, 7-10.

\section{Material examined}

\section{Holotype}

PERU: + , "North Peru, Rodriguez de Mendoza, 12.V.1996” (ZSMC, ex coll. FH 0219-1).

\section{Other material}

PERU: 1 ठૈ, "North Peru, Rodriguez de Mendoza, 3.1996” (FH, No. 0219-2).

\section{Description}

Male (Fig. 20)

Body. Size medium (body length $48.5 \mathrm{~mm}$ ), form very slender, legs entirely unarmed. Thorax very sparingly granulose.

CoLour. General colouration (of preserved specimen) dark blackish brown, most of meso- and metathorax dull greyish brown, the former with a few pale cream granules along lateral margins. Largest granules of abdominal sternum VIII and poculum pale cream to white; longitudinal carinae of terminal abdominal segments mid brown. Enlarged granules of mesonotum black. Cheeks with a very fine pale longitudinal postocular line. Legs with faint dull ochraceous mottling and femora becoming reddish mid brown towards base. Antennae blackish brown basally and gradually becoming pale brown towards apex.

HEAD. Elongate, subcylindrical, broadest at eyes and gently narrowed towards posterior with vertex flattened, some $1.6 \times$ as long as wide. Frons slightly convex and with a small V-shaped impression behind bases of antennae. Eyes fairly small, cylindrical and moderately projecting, their length contained almost $2 \times$ in that of cheeks. Antennae almost as long as body; scapus compressed dorsoventrally and about $1.3 \times$ as long as wide, roughly rectangular in shape. Pedicellus subcylindrical and about half length 
of scapus. Antennomere III almost as long as scapus and pedicellus combined; IV only about $0.4 \times$ length of III, $\mathrm{V}$ almost as long as III.

THORAX. Pronotum about as long but a little narrower than head, rectangular; disc with a fine, impressed longitudinal median line, transverse median sulcus distinct, very gently curved and expanding over entire width of segment. Mesothorax very elongate and almost $7 \times$ as long as prothorax. Mesonotum smooth dorsally and very minutely granulose laterally; dorsal portion supplied with about ten fairly large nodes and about six smaller, pale cream nodules along lateral margins. Metanotum less than half length of mesonotum and smooth except for about four somewhat enlarged granules.

AвDOMEN. Median segment less than $0.2 \times$ length of metanotum, gently constricted medially and about $1.2 \times$ as long as wide. Segments II and III about equal in length, IV-VII gradually decreasing in length, with VII about $3 / 4$ length of II; all gently constricted medially. II-V about $3 \times$ as long as wide. Tergum VIII somewhat shorter than VII and very slightly widening towards posterior; surface very minutely and sparsely granulose and lateral surfaces with a faint longitudinal carina. IX a little longer than VIII, constricted pre-medially and with the two lateral longitudinal carinae more decided than on VIII; surface minutely and sparsely granulose. Anal segment wider than all preceding, narrowed basally, with median portion somewhat deflexed and then gradually narrowed towards posterior; posterior margin with a wide and shallow concave emargination and outer angles bluntly triangular (Fig. 21); dorsal surface with an acute longitudinal median carina, which becomes increasingly less defined towards base, and a row of blunt tubercles laterally. Ventral surface of posterior margin with a few minute denticles in median portion. Vomer small, triangular in shape and with a moderately acute terminal hook. Cerci fairly large, almost as long as anal segment, gently curved, constricted basally and with apex club-like (Fig. 22). Poculum strongly convex, bowl-shaped with a blunt central projection (Fig. 22), dorsal carina labiate and downcurving if seen in lateral aspect and posterior margin with a shallow median indention; surface tuberculose (Fig. 23).
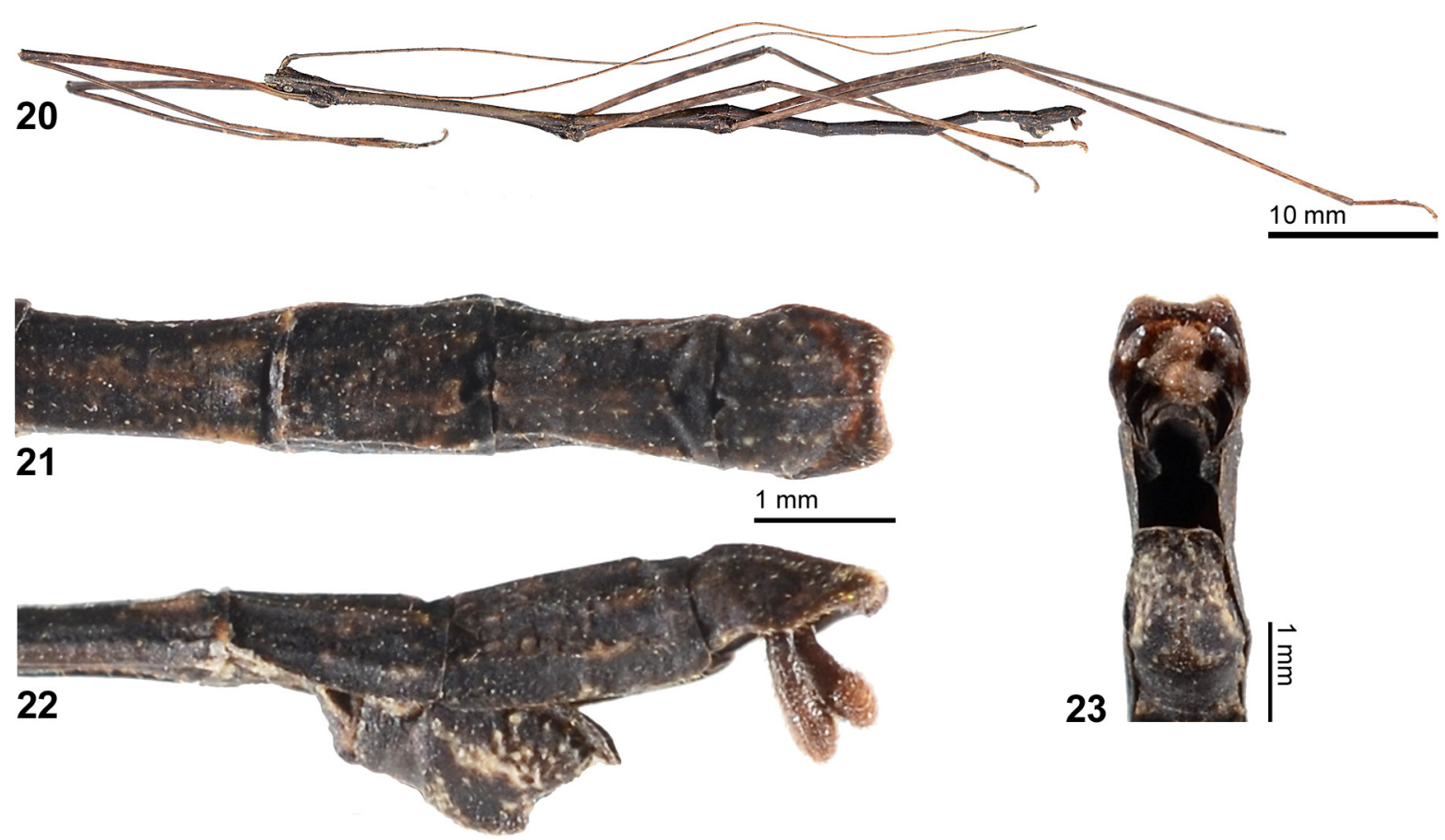

Figs 20-23. Lobolibethra mutica (Hennemann \& Conle, 2007). 20. § (FH, 0401-1). 21. §, apex of

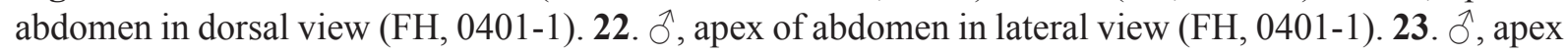
of abdomen in ventral view (FH, 0401-1). 
LEGs. All very long, slender and entirely unarmed. Profemora about as long as head, pro- and mesothorax combined, metafemora reaching to posterior margin of abdominal segment VII. Basitarsi a little longer than following three tarsomeres combined.

Measurements ( $\mathrm{mm}$ ): body length 48.5, pronotum 1.9, mesonotum 13.2, metanotum 7.9, median segment 1.7 , profemora 16.8 , mesofemora 11.8 , metafemora 15.7 , protibiae 19.8 , mesotibiae 15.0 , metatibiae 22.1, antennae 46.0.

\section{Remarks}

A male from the same source as the female holotype in the collection of the first author (FH) was not noticed when this species was described. A description of the previously unknown male appears warranted and is presented above. It may be easily distinguished from all other currently known males of the genus by its very slender form, relatively very elongate body segments, elongate head and comparatively small poculum. The eggs of $L$. mutica still remain unknown.

Lobolibethra panguana Hennemann \& Conle, 2007

Lobolibethra panguana Hennemann \& Conle, 2007: 98, figs 11-23, 32-33, 38-40.

\section{Material examined}

\section{Holotype}

PERU: +, "Peru, Dep. Huanuco, Rio Yuyapichis, Nebenfluß d. Rio Pachitea, ZSM-Forschungsstation Panguana, 973'S, 7456'W, 260m, 22.09.- 03.10.2004, leg. O. Conle \& F. Hennemann" (MUSM).

\section{Paratypes}

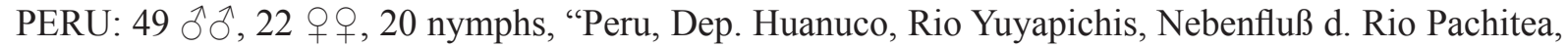
ZSM-Forschungsstation Panguana, 9'73'S, 74'56'W, 260m, 22.09.-03.10.2004, leg. O. Conle \&

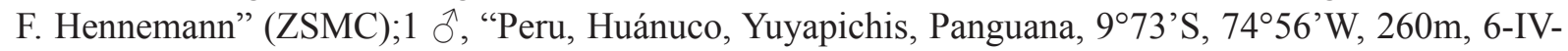

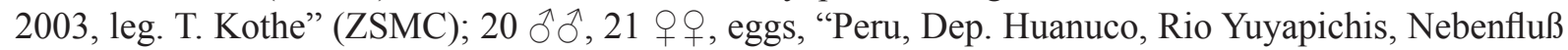
d. Rio Pachitea, ZSM-Forschungsstation Panguana, 973'S, 745'' W, 260m, 22.09.-03.10.2004, leg. F. Hennemann \& O. Conle" (FH 0552-1-41 \& E1); 3 के $\widehat{\partial}, 1$ q, 1 q (penultimate instar nymph), eggs, "ex

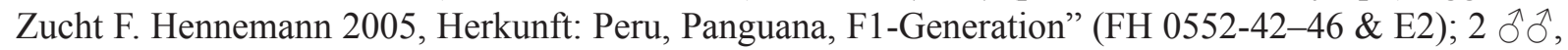
1 q, "ex Zucht F. Hennemann 2006, Herkunft: Peru, Panguana, F2-Generation" (FH 0552-47-49);

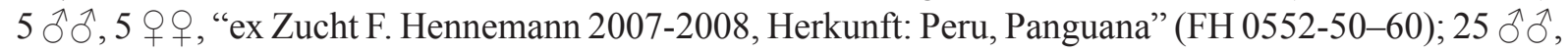
25 우, eggs, "Peru, Dep. Huanuco, Rio Yuyapichis, Nebenfluß d. Rio Pachitea, ZSM-Forschungsstation

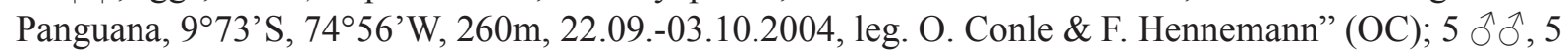
우: "ex Zucht O. Conle 2006, Zuchtstamm aus Peru, Panguana" (OC); 1 ô, 1 \&, "Peru, Dep. Huanuco, Rio Yuyapichis, Nebenfluß d. Rio Pachitea, ZSM-Forschungsstation Panguana, 9 ${ }^{\circ} 73^{\prime} \mathrm{S}, 7^{\circ}{ }^{\circ} 56^{\prime} \mathrm{W}$, 260m, 22.09.-03.10.2004, leg. O. Conle \& F. Hennemann" (MNHU); 1 §, 1 क , 3 eggs, "ex Zucht F. Hennemann 2006, Herkunft: Peru, Dep. Huanuco, Panguana" (NHMUK, ex FH).

\section{Other material}

PERU: 1 o, 1 ㅇ, "Peru Madre de Dios Rio Tambopata Res. 30km (air) sw Pto. Maldonato, 290m, $12^{\circ} 50^{\prime}$ S $069^{\circ} 20^{\prime}$ W" (USNM).

\section{Remarks}

A male and female from Río Madre de Dios in the Tambopata National Reserve (Dept. Tambopata) in the collection of USNM deserve special mention since they represent the first definite record of this highly variable species from elsewhere than the type locality. Both specimens have the armature of all 
tibiae comparatively more pronounced than any examples of the large type series, which comprises 216 specimens in total. Body lengths of the two specimens in USNM are male $61.0 \mathrm{~mm}$ and female $64.5 \mathrm{~mm}$, and hence are in the usual range of L. panguana. The authors have also seen photographs of L. panguana taken at Manú National Park in the Madre de Dios Region, but there are no reference specimens.

Lobolibethra pozuzoae sp. nov. urn:1sid:zoobank.org:act:25DD6299-E195-4305-8B3E-90C7B159CB91

Figs 24-39, 59-60

\section{Diagnosis}

Closely related and similar to L. carbonelli sp. nov. but differing by the on average larger size, somewhat more slender body and relatively longer body segments of both sexes. Females can also be distinguished by the less convex subgenital plate (Figs 31,33), which lacks the lateral projections seen in L. carbonelli sp. nov. and has the lateral margins more distinctly excavated, the straight posterior margin of the anal segment, which is quadri-dentate in the median portion (Figs 30,32), as well as the somewhat less developed ventral lobes of the mesofemora. Males are readily distinguished by the smooth meso- and metanotum (Fig. 29, granulose to nodulose in L. carbonelli), distinct concave posterior excavation of the lateral margins of the anal segment (Fig. 36) and less sculptured poculum, which has the posterior margin entire and broadly rounded (Fig. 37). The eggs differ by the somewhat less elongate capsule and shorter micropylar plate, which covers only about $2 / 3$ of the dorsal egg surface (Figs $38-39,3 / 4$ in L. carbonelli).

\section{Etymology}

Named after the type locality Pozuzo, an Austrian-German colony at the Río Huancabamba founded in 1859 and situated in the Pozuzo district of the Departemento Pasco, Province Oxapampa.

\section{Material examined}

\section{Holotype}

PERU: + , "Pozuzo, Sd. Peru, 800 m” (MHNG).

Paratypes (128 $\hat{\partial} \hat{\partial}, 132 \propto+q, 1$ nymph, eggs)

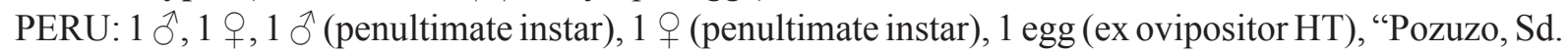
Peru, 800 m” (MHNG); đ, "ex Zucht. F. Hennemann 2008, Herkunft: SE-Peru, F2-Generation; ex coll. FH” (ZSMC); 5 ふ̊̊, 8 우, “ex Zucht. F. Hennemann 2007/08, Herkunft: SE-Peru, F1-Generation” (FH, 0631-1 to 15); 8 $\widehat{\jmath}, 8$ 우우, eggs (laid by F1-generation), "ex Zucht. F. Hennemann 2008, Herkunft: SE-

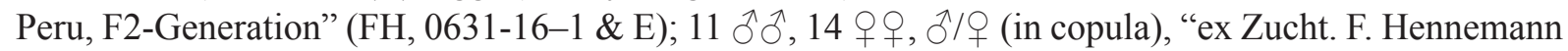

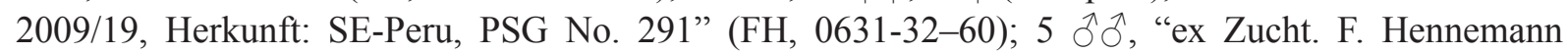
2010, Herkunft: SE-Peru, 2007, F3-Generation; ex coll. F. Hennemann” (MNHU); 55 ふぇ̊, 54 우우, eggs , "Ex Zucht: O. Conle 2007-2009, Peru: SE-Peru" (OC, No’s 0400-1-109); 100 eggs, "Ex Zucht:

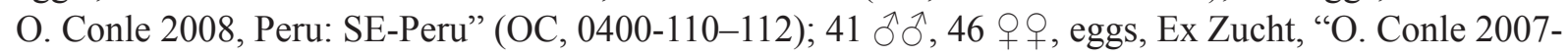
2009, Peru: SE-Peru; Ex Coll. Conle" (ZSMC).

\section{Description}

Female (Figs 24-26, 59)

Body. Size medium (body length 51.5-60.0 mm, Table 2), form moderately stocky, body surface tuberculose, rugulose and carinate to a variable degree and mid and hind legs just weakly lobed. Abdominal tergites II-IV often with a transverse scale-like posteromedian lobe, which is very variable in shape and size. 
Colour. Variable and ranging from tawny over reddish brown to dark greyish brown. Posterior lobes of abdominal tergites II-IV (if present) usually darker than rest of body and also some of the enlarged tubercles of mesonotum sometimes darker than rest of body. Antennae becoming increasingly paler towards apex. Basal portion of subgenital plate with a more or less defined dark elongate-triangular area medially.

HEaD. Elongate-oval with cheeks almost parallel-sided and vertex flattened; about $1.3 \times$ as long as wide. Posterior portion of vertex distinctly tuberculose and tubercles roughly arranged in four indicated longitudinal rows; terminal tubercles at posterior margin of head most prominent and spiniform. Frons slightly convex and vertex with a weakly defined coronal fissure. Occasionally a few small and irregularly dispersed tubercles on cheeks. Eyes small, sub-circular and their length contained about $2.7 \times$ in that of cheeks. Antennae projecting over posterior margin of abdominal segment III. Scapus
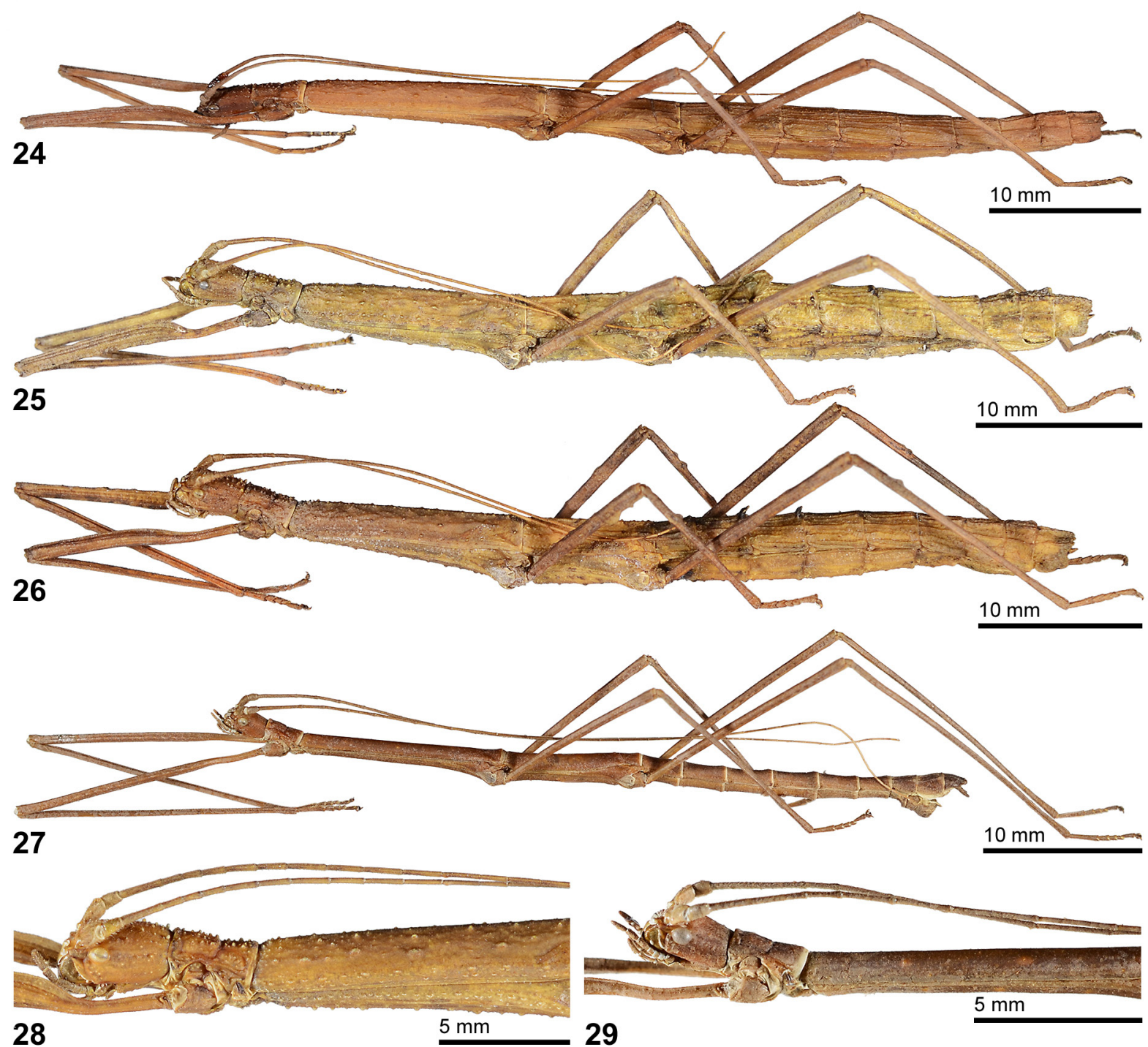

Figs 24-29. Lobolibethra pozuzoae sp. nov. 24. ㅇ, $\mathrm{PT}$ (FH, 0631-2). 25. ㅇ, $\mathrm{PT}(\mathrm{FH}, 0631-42)$. 26. ㅇ, PT (FH, 0631-44). 27. $\lesssim$, PT (FH, 0631-51). 28. ㅇ, PT: detail of head and thorax in lateral view (FH, 0631-35). 29. ${ }^{\pi}$, PT: detail of head and thorax in lateral view (FH, 0631-51). 
Table 2. Measurements of L. pozuzoae sp. nov. (in mm). HT = holotype; PT = paratype.

\begin{tabular}{|c|c|c|c|c|c|}
\hline & $\begin{array}{c}\text { P, HT } \\
\text { (MHNG) }\end{array}$ & $\widehat{\partial} \widehat{\partial}, \mathbf{P T}$ (FH) & $q q$, PT (FH) & $\begin{array}{c}\mathrm{O}^{1}, \mathbf{P T} \\
(\mathrm{MHNG})\end{array}$ & $\begin{array}{c}\text { O, PT } \\
\text { (MHNG) }\end{array}$ \\
\hline Body & 54.5 & $42.0-47.8$ & $51.5-60.0$ & ca 43.0 & 52.3 \\
\hline Pronotum & 3.3 & $2.0-2.3$ & $2.9-3.4$ & 2.1 & 3.2 \\
\hline Mesonotum & 13.3 & $11.5-14.2$ & $12.4-15.8$ & 11.7 & 12.4 \\
\hline Metanotum & 6.1 & $6.2-6.8$ & $5.6-7.0$ & 6.3 & 5.6 \\
\hline Median segment & 1.8 & $1.2-1.3$ & $1.7-1.9$ & 1.2 & 1.7 \\
\hline Profemora & 14.3 & $13.6-17.5$ & $13.8-16.5$ & 15.0 & 13.2 \\
\hline Mesofemora & 10.8 & $10.5-12.9$ & $10.0-11.8$ & 10.7 & 9.3 \\
\hline Metafemora & 14.8 & $13.6-16.0$ & $13.7-15.5$ & 15.0 & 12.9 \\
\hline Protibiae & 15.7 & $15.8-21.6$ & $14.6-17.8$ & 17.9 & 14.7 \\
\hline Mesotibiae & 10.7 & $12.0-15.5$ & $10.9-12.8$ & 13.0 & 9.8 \\
\hline Metatibiae & 16.0 & $18.3-22.2$ & $16.0-18.2$ & 19.5 & 15.5 \\
\hline Antennae & $>29.0$ & $38.0-44.0$ & $31.0-37.0$ & 42.0 & $>26.0$ \\
\hline
\end{tabular}

compressed dorsoventrally, rounded rectangular with lateral margins very gently deflexed and rounded; about $1.3 \times$ as long as wide. Pedicellus cylindrical and somewhat tapered towards apex. Antennomere III very elongate and about as long as scapus and pedicellus combined; IV less than $1 / 3$ length of III.

ThORAX. Pronotum about as wide as but a little shorter than head, rectangular in shape and some $1.2 \times$ as wide as long. Transverse median sulcus displaced towards posterior, distinctly impressed, gently curved and expanding over entire width of segment. Surface supplied with several fairly acute tubercles (Fig. 28); these roughly arranged in two longitudinal rows. Mesothorax about $4.5 \times$ as long as prothorax, parallel-sided with only posterior portion gently widened. Mesonotum weakly tectiform and irregularly granulose to tuberculose, lateral surface with longitudinally directed rugulae which indicate a weakly defined longitudinal carina. Several tubercles enlarged and indicated lateral carina often with about 3-4 noticeably enlarged blunt conical tubercles (Fig. 28). A marginal row of small, elongate tubercles along lateral margins. Metanotum sculptured like mesonotum, but lateral longitudinal carinae considerably more decided. Meso- and metapleurae and sterna granulose and supplied with several irregularly dispersed blunt tubercles.

ABDOMEN. Median segment about $1 / 4$ length of metanotum and a little more than $2 \times$ as wide as long; surface with four longitudinal carinae. Segments II-VII roughly uniform in width, II-VI slightly increasing in length with VII about equal in length to II; II slightly transverse, V quadrate and VI a little longer than wide. Tergites II-IX with four longitudinal, sub-parallel carinae and a weakly defined, very fine longitudinal median carina; a further much less defined carina laterally. Two outer carinae supplied with a few minute tubercles and two inner carinae of tergum IX noticeably diverging, gradually raised towards posterior and occasionally each terminating in a rounded lobe or obtuse swelling (Figs 30-31). III and IV often with a scale-like transverse lobe posteromedially which is variable in size and shape; 
that on III always considerably larger than that on IV. Occasionally also a small lobe on tergum II. Sternites II-VII with two irregular longitudinal rows of blunt tubercles and a few small irregularly dispersed tubercles and nodes; on VII the two rows of tubercles each form a keel that is gradually raised towards the posterior. Praeopercular organ indistinct and merely represented by a slightly raised area posteromedially. Tergum VIII somewhat narrowing towards posterior, IX narrowest and wider than long. Anal segment longer than IX and slightly widened towards posterior, with lateral margins strongly deflexed and forming a blunt rounded posteriad directed lobe (Figs 31,33); dorsal surface with a very acute longitudinal median keel, posterior margin almost straight and obtusely multi dentate (Figs 30, 32). Epiproct very small and fully hidden under anal segment (Figs 30, 32). Cerci small, conical and slightly projecting beyond posterior margin of anal segment. Subgenital plate reaching about half way along anal segment (Fig. 34), tub-shaped, with dorsal margins strongly excavated and concave in median portion (Figs 31,33) and the apex obtusely rounded. Ventral surface with two blunt converging ridges

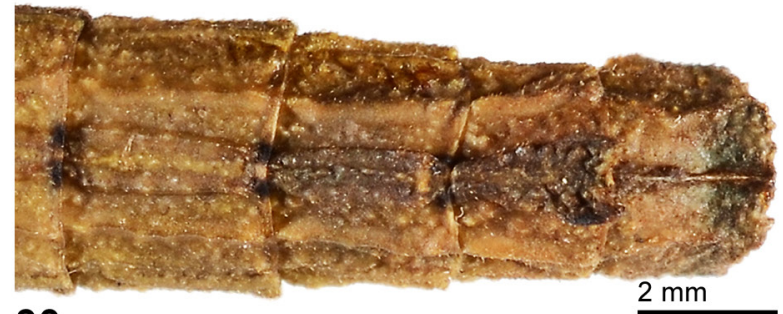

30

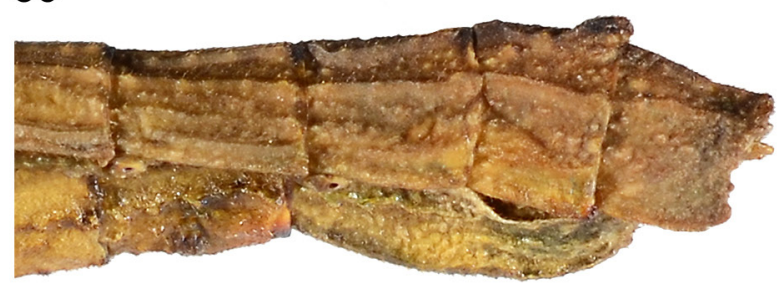

31

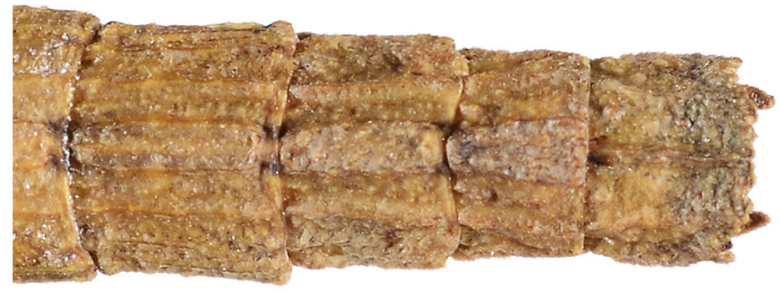

32

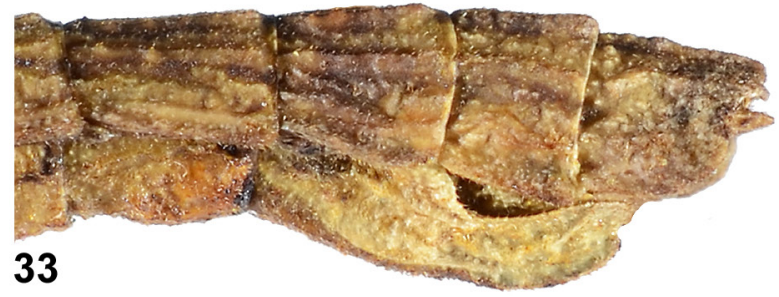

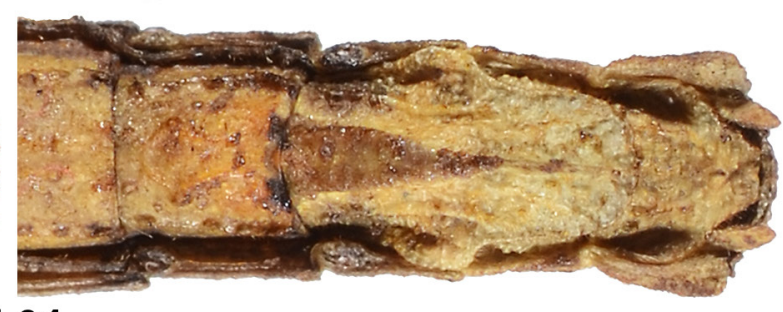

34
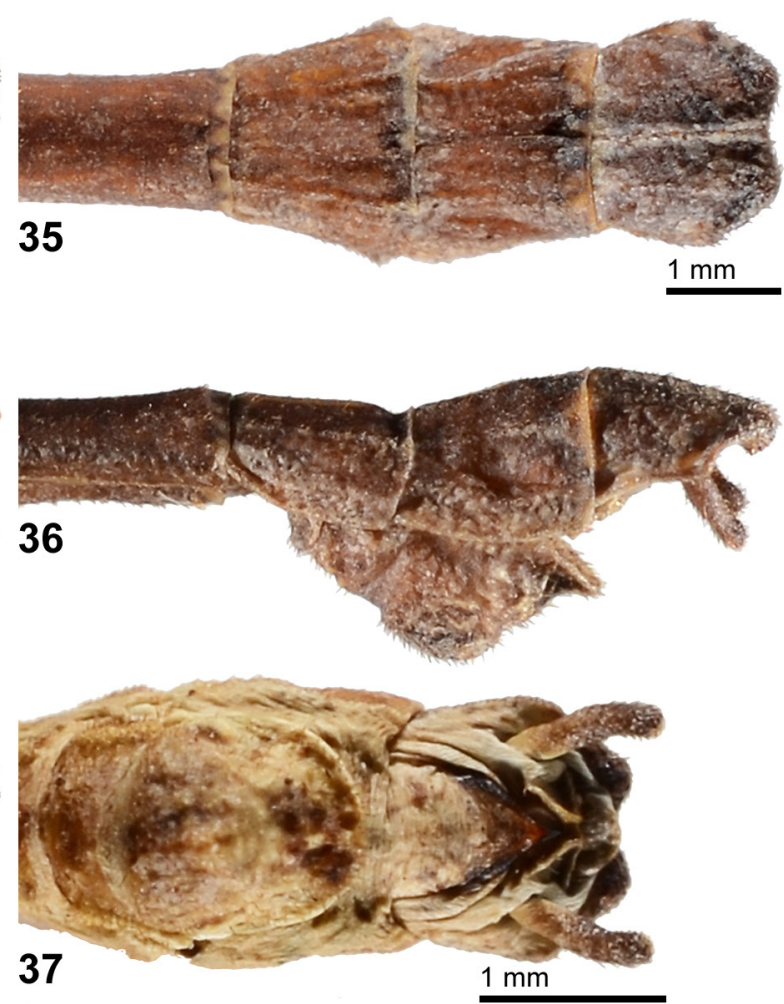

Figs 30-37. Lobolibethra pozuzoae sp. nov. 30. + , PT: apex of abdomen in dorsal view (FH, 0631-41). 31. $\odot$, PT: apex of abdomen in lateral view (FH, 0631-41). 32. $q$, PT: apex of abdomen in dorsal view (FH, 0631-44). 33. , PT: apex of abdomen in lateral view (FH, 0631-44). 34. , PT: apex of abdomen

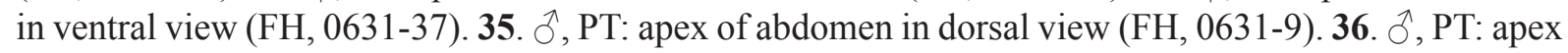
of abdomen in lateral view (FH, 0631-9). 37. $\mathrm{O}^{\wedge}$, PT: apex of abdomen in ventral view (FH, 0569-56). 
basally, which fuse about half way along subgenital plate to form a single blunt longitudinal keel on apical half; surface irregularly rugulose and tuberculose (Fig. 34).

LEGS. All moderately long and stocky, profemora a little longer than mesothorax and the metafemora roughly reaching to posterior margin of abdominal segment VI. Anterodorsal carina of profemora weakly undulate and posterodorsal carina of meso- and metatibiae with a small lobe sub-basally. Dorsal carinae and posteroventral carina of mesofemora only with very weakly indicated traces of lobes, anteroventral carina with three rounded lobes that increase in size towards apex; terminal sub-apical lobe variable in size. All tarsi short, with basitarsus about as long as following two tarsomeres combined.

Male (Figs 27, 60)

BoDy. Size medium (body length 42.0-47.8 mm, Table 2), form moderately slender for the genus; thorax smooth.

CoLour. Plain reddish mid brown, lateral surfaces of mesonotum each with two faint and weakly defined pale orange to yellowish spots in median portion. Anal segment mid to dark brown and noticeably darker than rest of body. Antennae pale brown basally darker, brown medially and pale ochre to straw apically.

HEAD. Sub-oval, broadest at eyes, with cheeks slightly sub-parallel and vertex flattened; smooth. Eyes sub-circular, strongly projecting and their length contained about $1.8 \times$ in that of cheeks. Antennae reaching to abdominal segment VII; otherwise as in females.

Thorax. Pronotum somewhat shorter and narrower than head and otherwise as in females; surface smooth. Mesothorax slender and $6 \times$ as long as prothorax. Surface of meso- and metathorax entirely smooth (Fig. 29).

AвDOMEN. Median segment about 1/7 length of metanotum, roughly as wide as long, with anterior margin gently rounded. Segments II-VII uniform in width, II-IV slightly increasing and V-VII decreasing in length; VII shorter than II. IV longest segment and about $2.3 \times$ as long as wide. Tergites very minutely granulose and granules roughly arranged in two longitudinal rows, sternites smooth. Tergum VIII trapezoidal and distinctly widened towards posterior, with posterior margin about $1.5 \times$ as wide as anterior margin; surface irregularly granulose and with two faint longitudinal carinae. IX about equal in length to VIII, gently narrowed towards posterior, slightly tectiform and with the two longitudinal lateral carinae noticeably more decided than on VIII. Anal segment shorter than preceding, lateral margins strongly deflexed in median portion and protruded into a blunt triangular tooth (Fig. 36); dorsal surface with a fine longitudinal median carina and two blunt, granulose longitudinal carinae; posterior margin distinctly excavated medially (Fig. 35), outer angles bluntly triangular, somewhat swollen and supplied with several minute denticles ventrally (Fig. 37). Cerci elongate, gently curved and slightly club-shaped, with an obtuse apex. Vomer well developed, triangular and with a fairly short but acute, straight terminal hook. Poculum strongly convex, bowl-shaped and irregularly rugulose; posterior margin somewhat labiate and broadly rounded (Fig. 37).

Legs. All long, slender and completely unarmed. Profemora a little longer than pro- and mesothorax combined, metafemora reaching to abdominal segment VIII and metatibiae projecing much beyond apex of abdomen. Tarsi moderately elongate, with basitarsus about as long as following three tarsomeres combined.

Egg (Figs 38-39)

Small, globose, $1.25 \times$ as long as than high and about $1.5 \times$ as long as than wide, slightly compressed laterally and oval in cross-section, with dorsal portion somewhat more convex than ventral portion. Capsule surface strongly shiny and very minutely granulose if seen in strong magnification. Micropylar 
plate elongate, slender, almost parallel-sided, with only posterior portion very gently widened and about $2 / 3$ length of capsule; conspicuously displaced towards anterior end of capsule. Central portion gently convex and the outer margin slightly swollen. Micropylar cup small and near posterior end of plate, median line distinct and very short. Operculum elliptical, gently downcurving dorsally and flat. In centre with a raised rim. Colour dark brown, with most of dorsal surface and anterior portion dull ochraceous; boardering section between these two differently coloured areas very dark blackish brown. Inner portion of micropylar plate dark reddish brown, outer portion and median line cream. Operculum dark brown, with central raised rim reddish mid brown. Measurements (in $\mathrm{mm}$ ): length 2.5, capsule length 2.4 , width 1.6, height 2.0, length of micropylar plate 1.7 .

\section{Remarks}

As in other species of the genus, considerable morphological variability is seen in females, but this is less noticeable than in, e.g., L. carbonelli sp. nov. or L. panguana Hennemann \& Conle, 2007. The abdominal tergites are unarmed or II-IV and IX bear posterior lobes. The scale-like transverse lobe on tergum III in particular shows considerable variability in size and shape. Variation is also seen in the size of the lobes of the anteroventral carina of the mesofemora and colouration. No noteworthy variability is seen in males.

The type locality Pozuzo is a small Austrian-German colony at the Río Huancabamba founded in 1859 and situated in the Pozuzo district of the Departemento Pasco, Province Oxapampa at an elevation of about $750 \mathrm{~m}$. The coordinates are $10^{\circ} 4^{\prime} \mathrm{S}, 75^{\circ} 32^{\prime} \mathrm{W}$. Culture stock was collected in 2007 from an unspecified locality but most certainly from somewhere in Oxapampa Province and eggs were forwarded to Bruno Kneubühler (Luzern, Switzerland) for breeding purposes. These eggs gave rise to a culture that was maintained for a few generations but was since lost. Bramble (Rubus fruticosus, Rosaceae), raspberry (Rubus idaeus, Rosaceae), roses (Rosa spp., Rosaceae) and oak (Quercus robur, Fagaceae) were accepted as alternative food plants. At average temperatures of $20-24^{\circ} \mathrm{C}$ in captivity males took about three and females about four months to reach maturity. Females produced some 10-12 eggs per week, which were simply dropped to the ground.
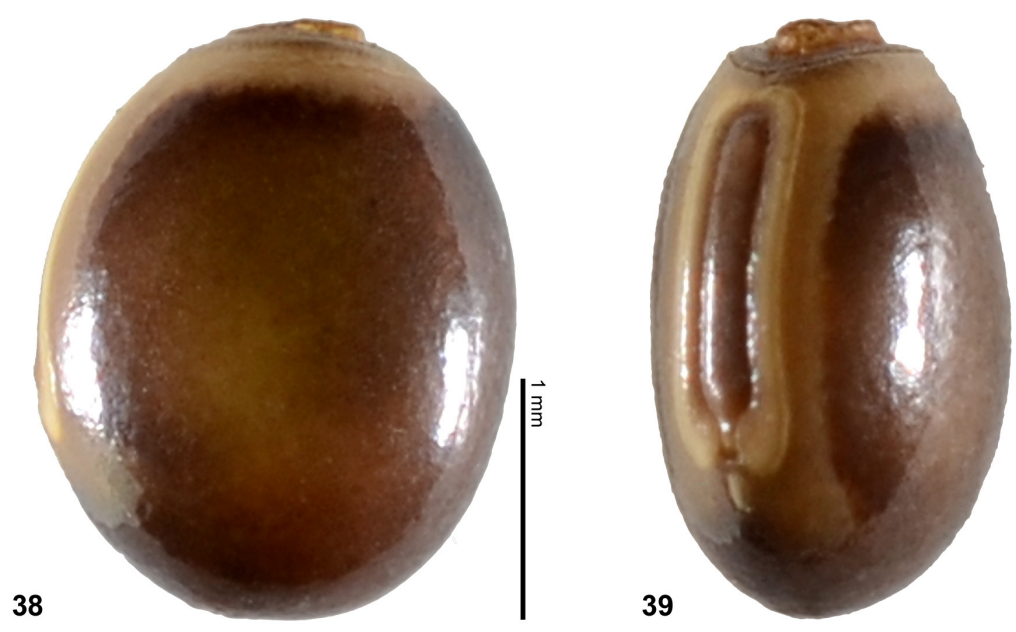

Figs 38-39. Lobolibethra pozuzoae sp. nov. 38. Egg, PT: lateral view (FH, 0631-E); 39. Egg, PT: dorsal view (FH, 0631-E). 


\section{Lobolibethra tricarinata sp. nov. urn:lsid:zoobank.org:act:36B8B5A8-CB01-4D03-8487-47777434E0AF}

Figs $40-51$

\section{Diagnosis}

Females of this new species resemble those of L. pozuzoae sp. nov. and L. mutica Hennemann \& Conle, 2007 in the general shape and weakly developed leg armature, but readily differ from both by the very distinct and acute longitudinal carinae of the dorsal body surface (meso- and metanotum in particular), complete lack of lobules on the mesofemora and less convex subgenital plate, which has the apical portion gradually flattened and narrowed towards a fairly acute triangular apex (Figs 41-42). From the former they may also be distinguished by the less deflexed and more weakly rounded lateral margins of the anal segment and from the latter by the presence of single enlarged conical to spiniform tubercles on the meso- and metanotum (Fig. 40). Males resemble those of L. mutica, but differ by the somewhat more stocky general habitus, carinate abdominal tergites, more bulgy poculum (Fig. 49), more prominent lateral nodes of the mesonotum and considerably longer antennomere IV.

\section{Etymology}

The name $($ carina Lat. $=$ keel) refers to the acutely tricarinate meso- and metanotum of females.

\section{Material examined}

\section{Holotype}

ECUADOR: + , "Ecuador: Prov. El Oro, ca 9.5 rd. km W. of Pinas, $900 \mathrm{~m}$, humid forest edge, $03.41 \mathrm{~S}$ 79.45 W, June 1985, G.S. Glenn" (ANSP).

Paratypes $(2 \hat{\jmath} \hat{\jmath}, 2$ 우 $)$

ECUADOR: 1 + , "Ecuador: Prov. El Oro, ca $9.5 \mathrm{rd}$. km W. of Pinas, $900 \mathrm{~m}$, humid forest edge, $03.41 \mathrm{~S}$ 79.45 W, June 1985, G.S. Glenn" (ANSP); 2 $\lesssim$, "Museum Paris, Equateur, S. Poulain rec.; Prov. El Oro, 5 km O. Pinas, 950 m, 18.IV.1990” (MNHN); 1 ㅇ, "No 68, El Salado, Raro" (MNCN).

\section{Description}

Female (Figs 40-42)

BoDy. Size medium for the genus (body length 58.0-61.0 mm, Table 3), form moderately slender, dorsal body surface with very distinct and acute longitudinal carinae; meso- and metanotum tricarinate.

Colour. General colour dull ochraceous to greyish brown. Cheeks with a very faint and weakly defined dark postocular streak.

HEAD. Oval, almost parallel-sided and about $1.3 \times$ as long as wide; vertex very gently convex with a fine longitudinal median coronal line and supplied with a few irregularly dispersed tubercles. Occassionally (paratype in ANSP) with a central pair of spiniform projections that are basaly constricted and medially swollen and with some of the coronal tubercles spiniform (Fig. 43). Eyes small, circular, fairly weakly projecting from head capsule and their length contained a little more than $3 \times$ in that of cheeks (Figs $43-$ 44). Scapus compressed dorsoventrally, oval in shape, with lateral margins convexely deflexed and about $1.5 \times$ as long as wide. Pedicellus much shorter and subcylindrical. III very elongate and almost as long as scapus and pedicellus combined. IV very short and only about 1/4 length of III (Figs 43-44).

THORAX. Pronotum about as long but a little narrower than head, rectangular and very gently narrowed medially; about $1.3 \times$ as long as wide. Almost over entire length with a slightly impressed longitudinal median fissure, transverse median sulcus distinct, somewhat displaced towards posterior, widely 


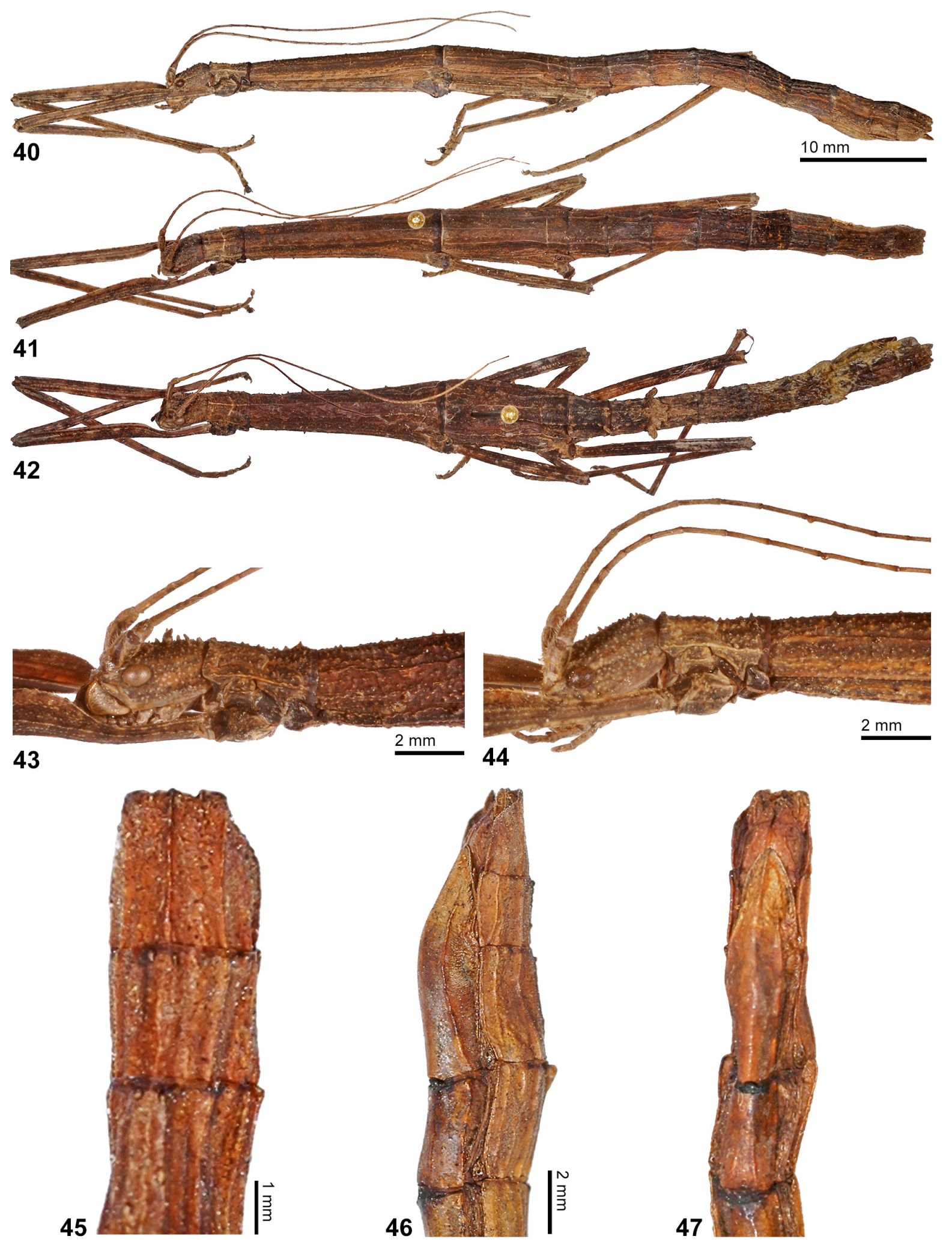

Figs 40-47. Lobolibethra tricarinata sp. nov. 40. $q$, HT: lateral view (ANSP). 41. $\odot$, HT: dorsal view (ANSP). 42. $q$, PT: dorsal view (ANSP). 43. + , PT: head and pronotum (ANSP). 44. $q$, HT: head and pronotum (ANSP). 45. ㅇ, PT: apex of abdomen in dorsal view (MNCN). 46. + , PT: apex of abdomen in lateral view (MNCN). 47. $\circ$, PT: apex of abdomen in ventral view (MNCN). 
Table 3. Measurements of $L$. tricarinata sp. nov. (in $\mathrm{mm}$ ). $\mathrm{HT}=$ holotype; $\mathrm{PT}=$ paratype.

\begin{tabular}{|c|c|c|c|c|}
\hline & †, HT (ANSP) & †, PT (ANSP) & q, PT (MNCN) & 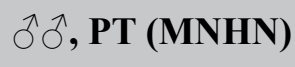 \\
\hline Body length & 61.0 & 58.0 & 59.9 & $55.0-60.5$ \\
\hline Pronotum & 3.3 & 3.1 & 3.2 & $2.2-2.7$ \\
\hline Mesonotum & 15.3 & 14.9 & 15.2 & $15.0-16.1$ \\
\hline Metanotum & 8.2 & 7.0 & 8.1 & $8.0-9.5$ \\
\hline Median segment & 2.4 & 2.3 & 2.3 & $1.9-2.1$ \\
\hline Profemora & 15.7 & 14.9 & 15.0 & $18.4-19.0$ \\
\hline Mesofemora & 11.0 & 10.5 & 10.8 & $13.2-13.4$ \\
\hline Metafemora & 14.4 & 14.0 & 13.5 & $16.0-17.0$ \\
\hline Protibiae & 16.0 & 15.1 & 15.8 & $20.5-20.2$ \\
\hline Mesotibiae & 11.0 & 9.3 & 11.5 & $14.5-14.9$ \\
\hline Metatibiae & 16.6 & 16.0 & 16.5 & $14.5-15.3$ \\
\hline Antennae & 40.0 & $>26.0$ & - & 43.0 \\
\hline
\end{tabular}

V-shaped and almost expanding over complete width of segment. Surface otherwise with a few tubercles and two slightly enlarged tubercles near posterior margin (Figs 43-44). Mesothorax about 4.6× as long as prothorax, roughly parallel-sided, with only posterior portion somewhat widened. Mesonotum with three distinctly raised and acute longitudinal carinae, irregularly granulose and with several considerably enlarged, conical to bluntly spiniform tubercles; lateral surfaces with several irregular, longitudinally directed rugulae and a marginal row of somewhat less pronounced tubercles. Metanotum sculptured like mesonotum and a little more than half its length. Meso- and metapleurae rugulose and set with a median longitudinal row of blunt tubercles. Meso- and metasternum sparingly granulose and rugulose.

ABDomen. Median segment less than $1 / 3$ length of metanotum, slightly transverse and with same three acute longitudinal carinae seen on the meso- and metanotum. Segments II-VII very slightly increasing in length and roughly uniform in width; II-III quadrate and following a little longer than wide. All tergites with five distinctly raised and acute longitudinal, sub-parallel carinae, inner three of which each terminate in a blunt tubercle at posterior margin (most distinct on II and III). Tergum III in one paratype (ANSP) with a prominent foliaceous quadrilobate, posteriorly directed projection (Fig. 42). VII and VIII with seven carinae, three inner ones on VII terminating in more or less distinct, rounded to foliaceous lobe. Tergum VII in one paratype (ANSP) with lateral margins convexely deflexed in posterior half to form a rounded lobe that extends width of segment by about $1 / 4$. Sternites II-VII with two slight longitudinal carinae which converge at posterior margin, which is otherwise set with two black tubercles. Praeopercular organ on sternum VII formed by a blunt black median swelling at posterior margin. Tergum VIII somewhat narrower than preceding and slightly narrowed medially, VIII-X roughly uniform in width. IX a litttle more than half length of VIII and roughly quadrate. Anal segment longer than IX, narrowed in apical portion, with posterior margin almost straight (Fig. 45); longitudinal median carina of dorsal surface strongly pronounced. Cerci very small and fully hidden under anal segment. Subgenital plate tub-shaped, with apical half gradually flattened (Fig. 46), keeled 
longitudinally and narrowed towards a fairly acute triangular apex (Fig. 47), lateral surfaces with a blunt curved longitudinal carina; apex reaching about $1 / 3$ the way along anal segment.

LEGs. Moderately long and stocky, destitude of any lobes, teeth or undulations, as in other species of the genus. Profemora a little shorter than mesothorax, metafemora reaching to posterior margin of abdominal tergum $\mathrm{V}$ and metatibia roughly reaching to apex of abdomen. Tarsi fairly short, with basitarsus a little less than combined length of following three tarsomeres.

Male (Figs 48-49)

Body. Size medium (body length 55.0-60.5 mm, Table 3), form moderately slender, legs entirely unarmed. Head and thorax very sparingly granulose and abdominal tergites II-VI with four fine longitudinal carinae.

CoLour. General colouration drab to ochraceous brown, meso- and metapleurae greyish dull brown. Enlarged granules of mesonotum dark brown. Cheeks with a bold but faint dull brown longitudinal postocular streak (Fig. 50). Antennae drab to dull ochraceous, with antennomeres IV-XI dull brown basally.

HeAD. Fairly elongate, subcylindrical, broadest at eyes, cheeks almost parallel-sided and vertex flattened; about $1.5 \times$ as long as wide. Frons slightly convex and with a small C-shaped impression behind bases of antennae. Entire surface irregularly set with variably sized pale granules and vertex with a fine longitudinal coronal line (Fig. 50). Eyes fairly small, cylindrical and projecting hemispherically, their length contained about $2 \times$ in that of cheeks. Antennae reaching to abdominal segment VII. Scapus compressed dorsoventrally, almost $2 \times$ as long as than wide and roughly rectangular, with interior margin gently convex. Pedicellus subcylindrical, about $2 / 3$ length of scapus and gently constricted towards apex.
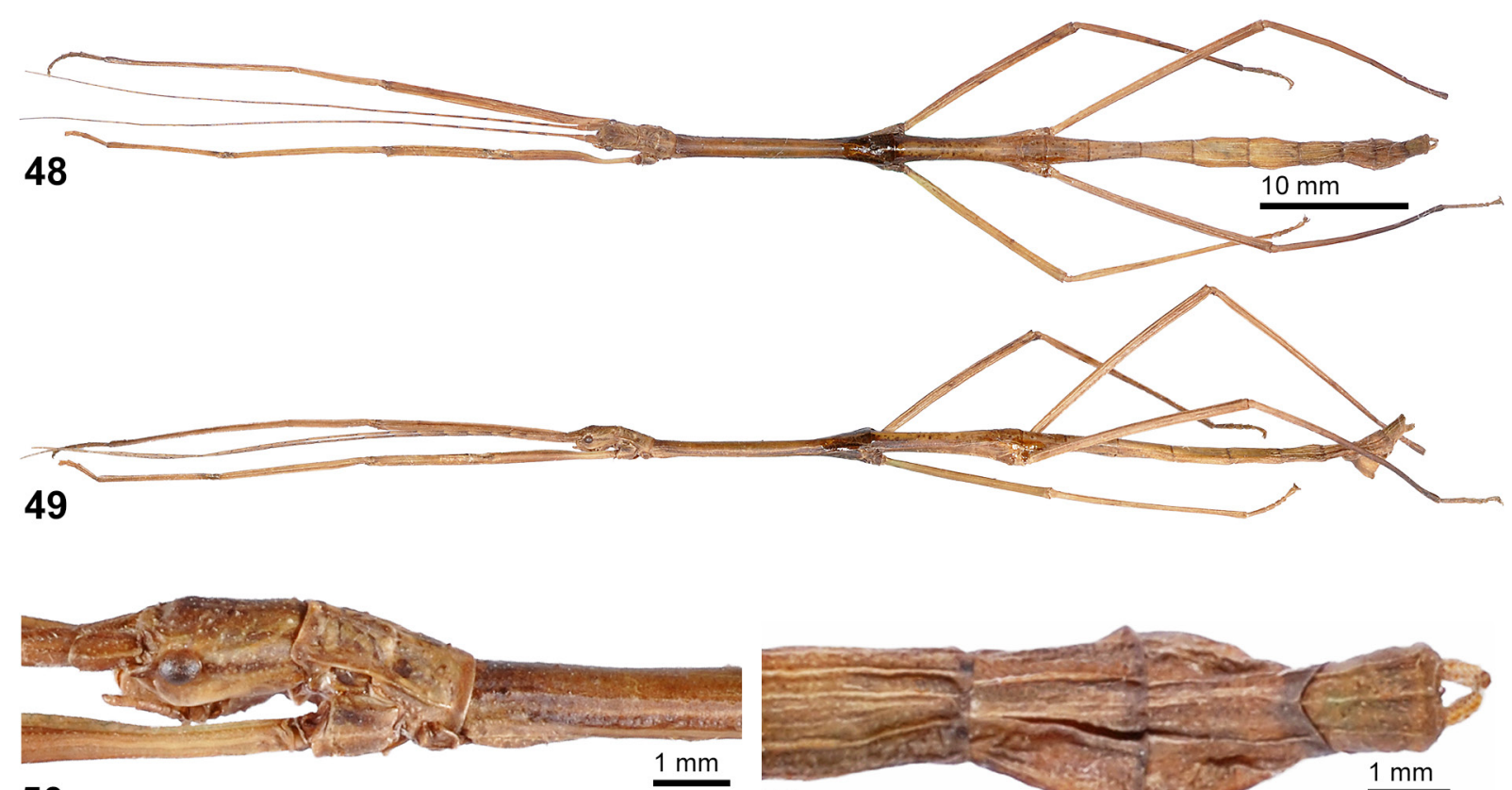

50

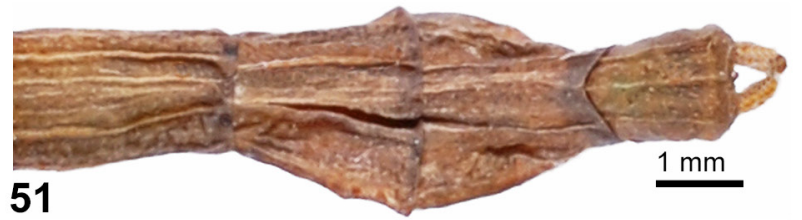

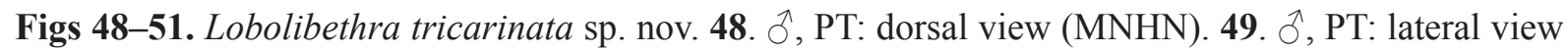
(MNHN). 50. ${ }^{\lambda}, \mathrm{PT}$ : head and pronotum in lateral view (MNHN). 51. $\widehat{\jmath}$, PT: apex of abdomen in dorsal view (MNHN). 
Antennomere III very elongate and longer than scapus and pedicellus combined; IV less than $2 / 3$ length of III.

Thorax. Pronotum about as long and wide as head, rectangular and weakly constricted medially; disc with a fine, impressed longitudinal median line and sparsely granulose, transverse median sulcus prominent, very gently curved and expanding over roughly half width of segment. Near posterior margin with a pair of slightly enlarged tubercles (Fig. 50). Mesothorax elongate and 5.5× as long as prothorax. Mesonotum indistinctly tricarinate with a fine longitudinal median carina and a very faint lateral carina that is marked by a longitudinal row of minute granules; lateral surfaces otherwise supplied with 5-7 small nodules. Metanotum a little more than half length of mesonotum but with carinae less defined and with only two or three very minute nodules laterally.

ABDOMEN. Median segment about $0.2 \times$ length of metanotum, gently constricted medially and roughly rectangular, with three longitudinal carinae weakly indicated. Segments II-VII uniform in width, II almost $2 \times$ as long as median segment, III-V longer than II, equal in length and some $2.4 \times$ as long as wide, V to VII decreasing in length. All quadricarinate, but carinae very indistinct on II and gardually become more defined towards VII. Tergum VIII about $2 / 3$ length of VII and gradually widening towards posterior, with posterior margin some $1.5 \times$ as wide as anterior margin, IX somewhat longer than VIII and narrowed towards posterior; both acutely quadricarinate. Anal segment narrower than two previous segments, longer than wide and distinctly tricarinate, with posterior portion somewhat expanded; posterior margin gently indented medially, with outer angles broadly and bluntly angular (Fig. 51), ventral surface minutely denticulate. Epiproct very small and slightly projecting over posterior margin of anal segment. Vomer triangular in shape, with lateral margins strongly swollen and median portion impressed; terminal hook strongly up-curving. Cerci fairly large, but much shorter than anal segment, laterally compressed at base and gently gradually constricted towards obtuse apex (Fig. 51). Poculum strongly convex, bowl-shaped, with a blunt central projection (Fig. 49), dorsal carinae labiate, posterior margin entire, somewhat expanded and slightly up-curving; surface rugulose.

Legs. All moderately long, slender and completely unarmed. Profemora a little longer than mesothorax, metafemora reaching to posterior margin of abdominal segment VI and metatibiae projecing considerably beyond apex of abdomen. Tarsi fairly short, with basitarsus about as long as following three tarsomeres combined.

\section{Remarks}

The three females at hand show that this species is fairly variable in several morphological aspects. While the holotype and paratype in MCSN are plain, the paratype in ANSP has foliaceous lobes on abdominal tergites II, III and VII. Furthermore, which is unusual for the entire genus, this specimen also has the posterolateral angles of abdominal tergum VII expanded to form a moderately sized, rounded lobe. The vertex bears a central pair of small spiniform projections that are constricted at their base and swollen in the median portion. The two paratypic males at hand are different in colouration, one being drab to ochre and the other somewhat darker ochraceous brown.

The coordinates for the type locality some kilometres east of Piñas in the El Oro Province of south Ecuador are $3^{\circ} 41^{\prime} \mathrm{S}, 79^{\circ} 45^{\prime} \mathrm{W}$ according to the labels of the ANSP specimens. El Salado, the locality of the female paratype in $\mathrm{MNCN}$, is a small town situated at an elevation of 1310 metres in Yacuambi, Zamora Chinchipe Province, southeast Ecuador. The coordinates are $3^{\circ} 38^{\prime} 39^{\prime \prime} \mathrm{S}, 78^{\circ} 55^{\prime} 25^{\prime \prime} \mathrm{W}$. Eggs unknown. 


\section{Lobolibethra verruculosa sp. nov. urn:lsid:zoobank.org:act:01D723D9-BB18-4F73-A91E-E26F97D05C81}

Figs 52-55

\section{Diagnosis}

While generally similar to $L$. carbonelli sp. nov., males of this new species readily differ from those of all other known species of the genus by their stocky and compact habitus and densely verruculose thorax.

\section{Etymology}

The name (verruculosus Lat. = verruculose, with many small warts) refers to the densely verruculose thorax of males of this new species.

\section{Material examined}

\section{Holotype}

PERU: đ̃, "Leonpampa 110 k. E. Huanaco, Huanaco Prov., Peru; Tropical Jungle, December 1937, Felix Woytkowski“ (ANSP).

\section{Description}

Male (Figs 52-53)

Body. Size fairly small (body length $43.8 \mathrm{~mm}$ ), form very robust and stocky for the genus; thorax strongly and densely granulose and verruculose.

CoLour. The preserved HT plain dull brown, the granules and warts of the thorax ochre. Legs with a slight reddish wash. Antennae reddish pale brown, but gradually darkening towards base, with scapus and pedicellus dull greyish brown.

Head. Sub-oval, broadest at eyes, with cheeks slightly sub-parallel and narrowed towards posterior; vertex flattened, vertex and upper portion of cheeks irregularly granulose and tuberculose, with some tubercles near posterior margin spiniform (Fig. 54). Eyes moderately sized, sub-circular, strongly projecting and their length contained about $2 \times$ in that of cheeks. Antennae reaching to posterior margin of abdominal segment III; scapus compressed dorsoventrally, rounded rectangular and about $1.5 \times$ as long as wide. Pedicellus cylindrical and less than half length of scapus. III very elongate and longer than scapus and pedicellus combined; IV a little more than half length of III (Fig. 54).

Thorax. Pronotum about as long but slightly narrower than head, rectangular and gently constricted medially, disc irregularly but densely granulose to verruculose; transverse median sulcus weakly defined, almost straight and expanding over entire width of segment. Mesothorax almost $5 \times$ length of prothorax. Surface of meso- and metanotum densely and strongly verruculose, mesonotum with a few more enlarged nodes along lateral margins. Meso- and metapleurae and sterna verruculose, but comparatively less distinct than nota.

Abdomen. Median segment a little more than $1 / 5$ length of metanotum and some $1.3 \times$ as wide as long; surface as in metanotum. Segments II-VII almost uniform in width, II-IV slightly increasing and V-VII decreasing in length; VII shorter than II. IV longest segment and about $1.6 \times$ as long as wide. Tergites II-VII very minutely granulose and sparsely verruculose laterally, all with weakly indicated sub-parallel longitudinal carinae which become increasingly defined towards VII; one of lateral carinae somewhat more distinct than remaining one. VIII somewhat shorter than VII and gradually widening towards posterior, with longitudinal carinae more defined than on preceeding tergites. IX about equal in length to VIII and slightly narrowed towards posterior. Anal segment a little longer than IX and somewhat 
expanded pre-posteriorly, lateral margins with a blunt tooth-like projection post-medially (Fig. 55) and posterior margin with a broadly rounded, concave median excavation; outer angles bluntly angular and ventral surface minutely denticulate. Cerci of moderate size, arcuate, in-curving and slightly club-like. Vomer broadly triangular, with lateral margins slightly swollen and terminal hook strongly up-curving; outer portions dull reddish brown and central portion dark blackish brown. Poculum moderately convex, bowl-shaped, with complete surface rugulose and scabrous; posterior margin strongly labiate and with a distinct, rounded median indention (Fig. 55).

Legs. All moderately long, slender and completely unarmed. Profemora somewhat longer than mesothorax, metafemora reaching to abdominal segment VIII and metatibiae projecing strongly beyond apex of abdomen. Tarsi moderately elongate, with basitarsus a little longer than following three tarsomeres combined.

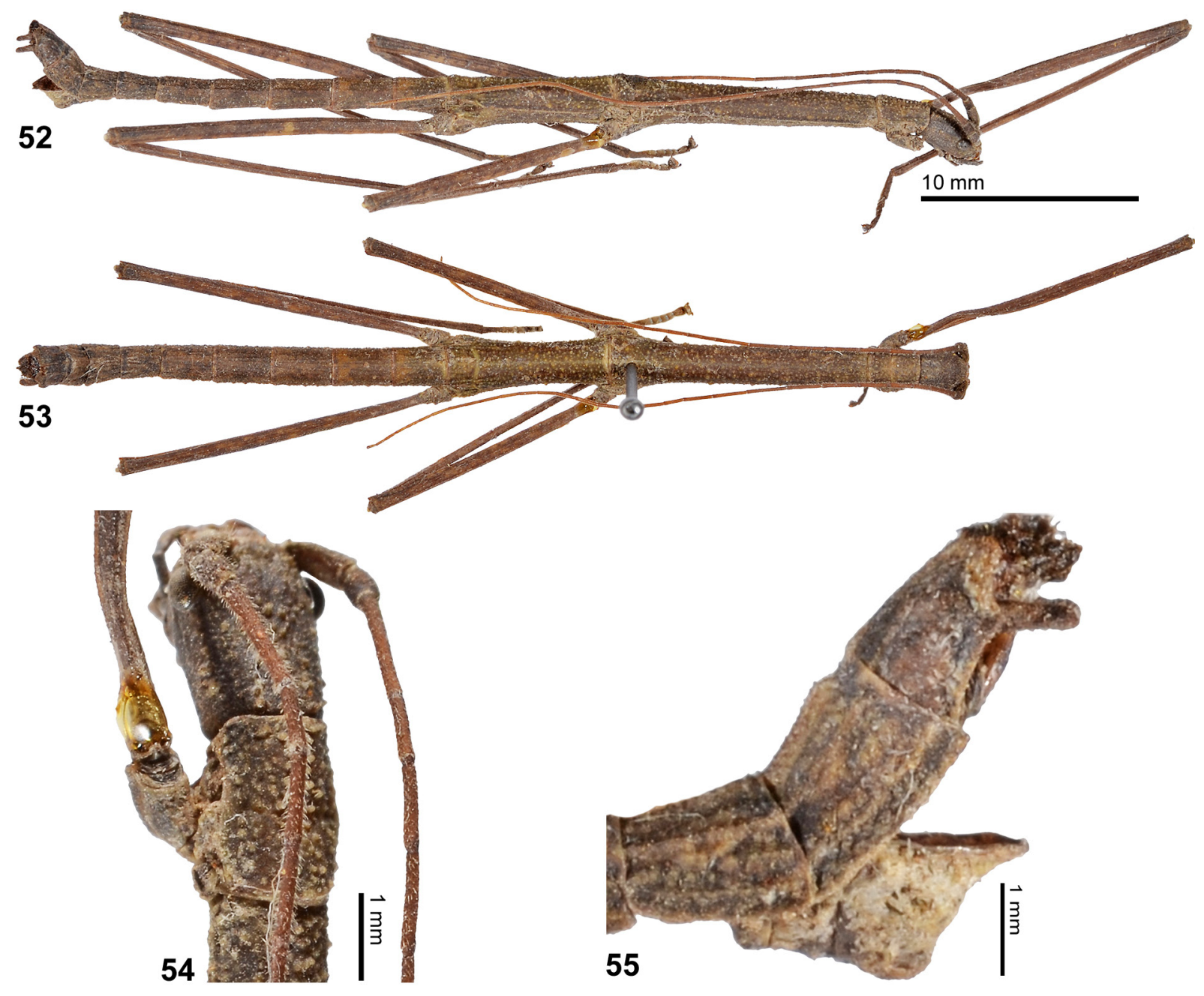

Figs 52-55. Lobolibethra verruculosa sp. nov. 52. $\curvearrowright$, HT: lateral view (ANSP). 53. (ANSP). 54. ${ }^{\lambda}$, HT: head and pronotum in dorsal view (ANSP). 55. ${ }^{\lambda}$, HT: apex of abdomen in lateral view (ANSP). 

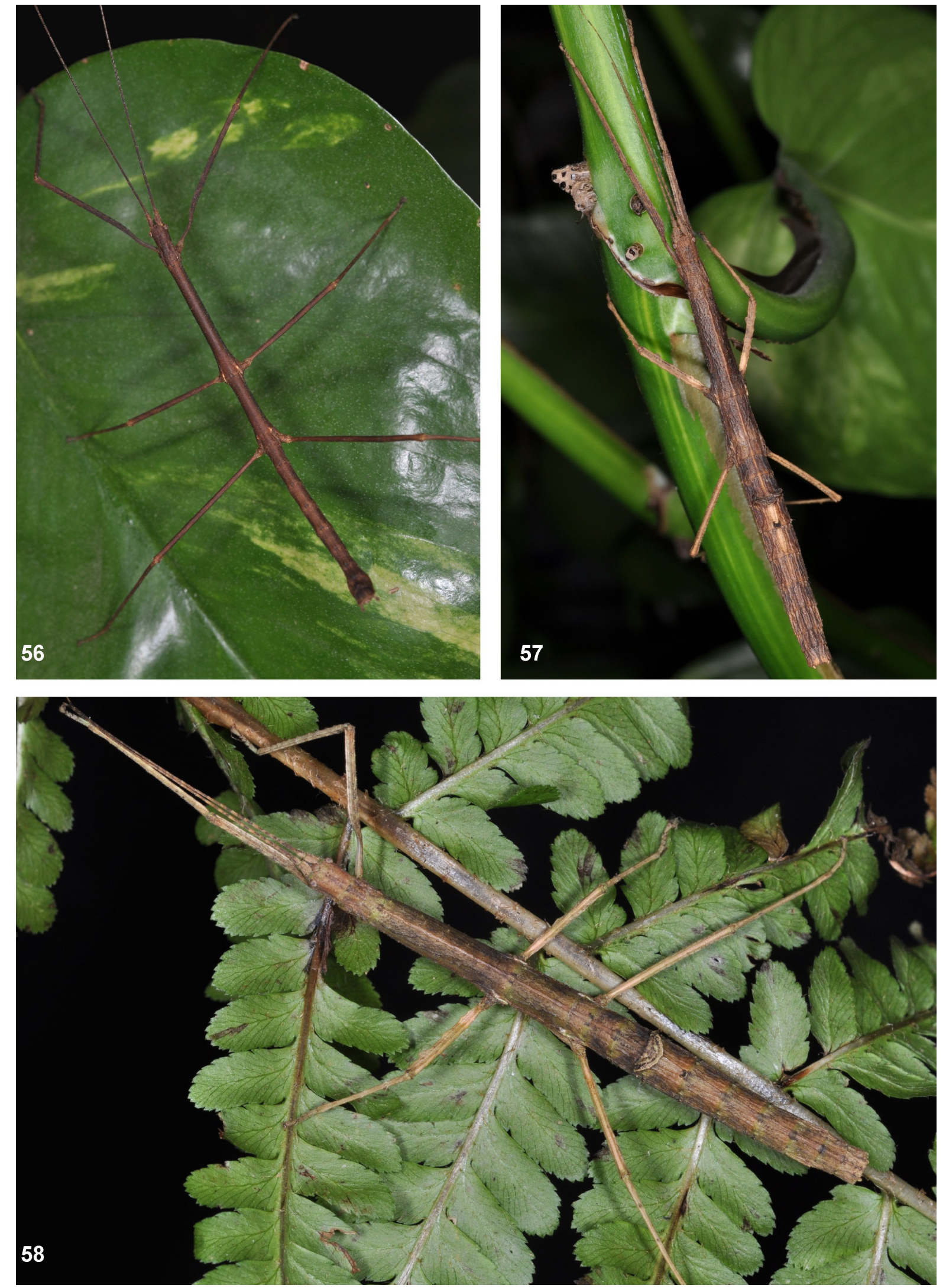

Figs 56-58. Lobolibethra carbonelli sp. nov. 56. Live ${ }^{\Uparrow}$, PT (FH). 57. Live $q$, PT (FH). 58. Live + , PT (FH). 

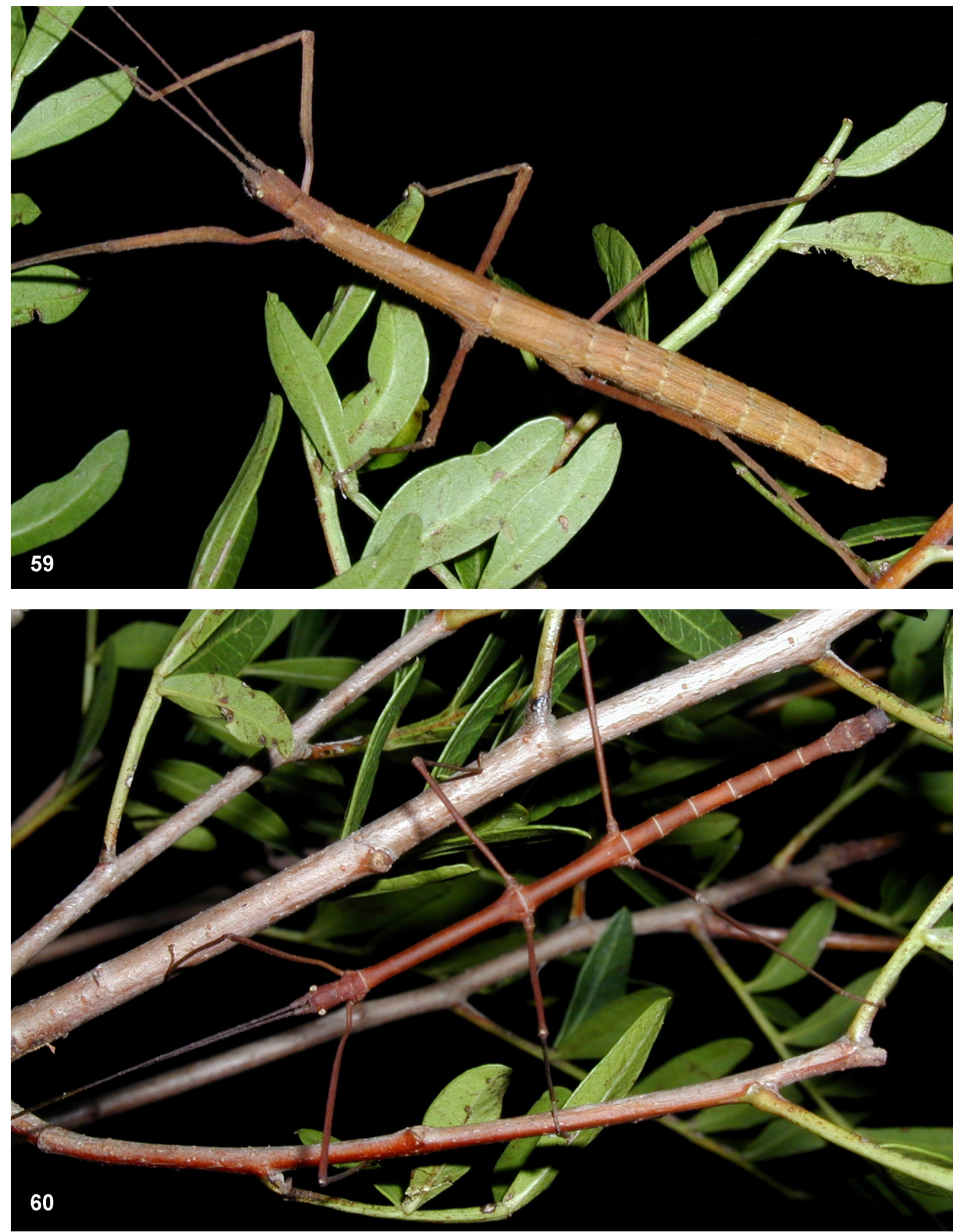

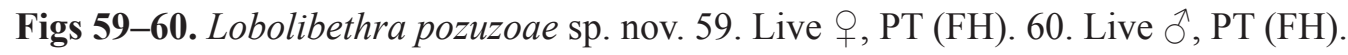


Measurements (in $\mathrm{mm}$ ): body length 43.8 , pronotum 2.2, mesonotum 12.0, metanotum 5.9, median segment 1.5, profemora 12.6, mesofemora 10.7, metafemora 13.9, protibiae 14.0, mesotibiae 12.2, metatibiae 17.2, antennae 30.0.

\section{Remarks}

The type locality "Leonpampa" probably refers to present-day San Luis de León Pampa $\left(9^{\circ} 633^{\prime}\right.$ S, $76^{\circ} 067^{\prime} \mathrm{W}$ ) in Departemento Huánuco. So far only known from the unique male holotype in ANSP. Female and egg unknown.

\section{Discussion}

New information on the genus Lobolibethra Hennemann \& Conle, 2007, including the descriptions of four new species from Peru and Ecuador, as well as the descriptions and illustrations of the previously unknown males of two species, have been presented. This considerably broadens our knowledge of Lobolibethra, a genus that belongs in a very species-rich and widely distributed generic complex of the subfamily Diapheromerinae, currently regarded as the "Clonistria-group". Five of the eleven recognized species are currently only known from single specimens; hence, it is believed that the genus is still poorly known and it is expected that several further species await discovery and description. Also, still very little is known about the natural food plants of Lobolibethra species. The wide distributional range includes great portions of the Amazon Basin and the moist tropical rain forests along the eastern slopes of the Andes up to elevations of almost 2000 metres. According to Morrone (2006: 472, 473), the known distribution refers to the Amazonian subregion of the Neotropical region (biogeographical Provinces Yungas, Napo, Varzea, Ucayali and Madeira) and to the eastern sections of the South American Transition Zone (biogeographical Province Puna). As in most representatives of Diapheromerinae, the strong sexual dimorphism in Lobolibethra makes the to match of sexes very difficult. Thus, it is hoped that future collections will contain more material of this genus to broaden our knowledge, but with both sexes from the same locality in particular to enable us matching the corresponding males and females. The authors have examined several further specimens of supposedly still undescribed species that are not covered in the present study. The reasons for this include that the single specimens are either in bad condition or lack precise collecting data, or are fairly cryptic females that based on a single specimen could not be sufficiently differentiated from closely related species.

\section{Acknowledgements}

The authors want to express their thanks to the following curators for access to the corresponding collections and loan of specimens: Judith Marshall and Dr George Beccaloni (NHMUK, London), Dr Michael Ohl (MNHU, Berlin), Dr Peter Schwendinger (MHNG, Geneva), Daniel Perez-Gelabert (USNM, Washington DC), Dr Daniel Otte and Jason Weintraub (ANSP, Philadelphia), Dr Isabel Izquierdo and Mercedes París (MNCN, Madrid), Dr Tony Robillard (MNHN, Paris), Dr Mauro Daccordi and Dr P.L. Scaramozzino (MIZT, Torino) and Dr Roberto Poggi (MCSN). Paul D. Brock (NHMUK, London) kindly took detailed pictures of type specimens in USNM and allowed the usage of some pictures in this study. Dr Bruno Kneubühler (Luzern, Switzerland) is thanked for providing livestock of L. carbonelli and L. pozuzoae for breeding purposes. Dr John T. Clark Sellick (Kettering, U.K.) kindly donated eggs of the original culture stock of PSG No. 51, here described as L. carbonelli. Marvin Uhlig (Oberreute, Germany) is thanked for compiling the plates. 


\section{References}

Brunner v. Wattenwyl C. \& Redtenbacher J. 1906-1908 Die Insektenfamilie der Phasmiden I-III. Verlag von Wilhelm Engelmann, Leipzig.

Caudell A.N. 1918. On a collection of Orthoptera (exclusive of the Locustidae) made in central Peru by N. Iconnicoff and C. Schunke. Insecutor Inscitiae Menstruus 6 (1-3): 1-70.

Clark Sellick J.T. 1997. Descriptive terminology of the phasmid egg capsule, with an extended key to the genera based on egg structure. Systematic Entomology 22: 97-122.

https://doi.org/10.1046/j.1365-3113.1997.d01-30.x

Clark Sellick J.T. 1998. The micropylar plate of the eggs of Phasmida, with a survey of the range of plate form within the order. Systematic Entomology 23: 203-228.

https://doi.org/10.1046/j.1365-3113.1998.00056.x

Conle O., Hennemann F. \& Gutiérrez. Y. 2011. The Stick Insects of Colombia. A Catalogue and Bibliography with the Descriptions of Four New Genera and 74 new Species. Books on Demand GmbH, Norderstedt, Germany.

Giglio-Tos E. 1898. Viaggio del Dr. Enrico Festa nella Republica dell'Ecuador et regioni vicine. VI. Ortotteri. Bollettino dei Musei di Zoologa ed Anatomia comparata della Reale Università di Torino 13 (311): 1-108.

Giglio-Tos E. 1910. Fasmidi esotici del R. Museo zoologico di Torino e del Museo civico di Storia naturale di Genova. Bolletino dei Musei di Zoologa ed Anatomia comparata della Reale Università di Torino 25 (625): 1-57.

Günther K. 1940. Über die Verbreitung einiger Insekten im Gebiete des Amazonenstromes und die Frage eines columbischen Faunendistriktes in der brasilianischen subregion. Archiv für Naturgeschichte, N. F. 9: 450-500.

Hennemann F.H. \& Conle O.V. 2007. Studies on neotropical Phasmatodea VII. Descriptions of a new genus and four new species of Diapheromerinae from Peru and Bolivia (Phasmatodea: "Anareolatae": Diapheromeridae). Mitteilungen der Münchner Entomologischen Gesellschaft 97 (Suppl.), 89-112.

Kirby W.F. 1904. A Synonymic Catalague of Orthoptera. 1. Orthoptera Euplexoptera, Cursoria et Gressoria. (Forficulidae, Hemimeridae, Blattidae, Mantidae, Phasmidae). British Museum, London. Available from https://www.biodiversitylibrary.org/page/6196392\#page/9/mode/1up [accessed 12 Jun. 2018]

Morrone J.J. 2006. Biogeographic areas and transition zones of Latin America and the Caribbean Islands based on panbiogeographic and cladistic analyses of the entomofauna. Annual Review of Entomology 51: 467-494. https://doi.org/10.1146/annurev.ento.50.071803.130447

Otte D. \& Brock P. 2005. Phasmid Species File. Catalog of Stick and Leaf Insects of the World, $2^{\text {nd }}$ edition. The Insect Diversity Association and the Academy of Natural Sciences, Philadelphia. CafePress.com.

Stål C. 1875. Recensio Orthopterorum III. Revue critique des Orthoptères déscrits par Linné, de Geer et Thunberg. P.A. Norstedt \& Söner, Stockholm.

Westwood J.O. 1859. Catalogue of Orthopterous Insects in the Collection of the British Museum. Part 1: Phasmidae. Trustees of the British Museum, London.

Zompro O. 2003. Catalogue of type material of the insect order Phasmatodea deposited in the Museum für Tierkunde, Dresden, Germany. Phasmid Studies 11 (2): 31-44. 
Zompro O. 2004. Revision of the genera of the Areolatae, including the status of Timema and Agathemera (Insecta, Phasmatodea). Abhandlungen des naturwissenschaftlichen Vereins in Hamburg (N.F.) 37: $1-327$.

Manuscript received: 28 May 2017

Manuscript accepted: 28 November 2017

Published on: 12 July 2018

Topic editor: Gavin Broad

Desk editor: Jeroen Venderickx

Printed versions of all papers are also deposited in the libraries of the institutes that are members of the EJT consortium: Muséum national d'Histoire naturelle, Paris, France; Botanic Garden Meise, Belgium; Royal Museum for Central Africa, Tervuren, Belgium; Natural History Museum, London, United Kingdom; Royal Belgian Institute of Natural Sciences, Brussels, Belgium; Natural History Museum of Denmark, Copenhagen, Denmark; Naturalis Biodiversity Center, Leiden, the Netherlands; Museo Nacional de Ciencias Naturales-CSIC, Madrid, Spain; Real Jardín Botánico de Madrid CSIC, Spain; Zoological Research Museum Alexander Koenig, Bonn, Germany. 